\title{
A SISTEMÁTICA Rb/Sr EM ROCHAS GRANITÓIDES: CONSIDERAÇÕES INTERPRETATIVAS, LIMITAÇŌES E EXEMPLOS BRASILEIROS
}

\author{
SILVIO ROBERTO FARIAS VLACK* e UMBERTO GIUSEPPE CORDANI**
}

\begin{abstract}
A literature review about the $\mathrm{Rb} / \mathrm{Sr}$ systematics in undertaken, as applied to granitoid rocks, poiting out potentials and interpretation limitations. Ages derived from $\mathrm{Rb} / \mathrm{Sx}$ isochrons pinpoint either crystallization or post-crystallization homogenization events. Isochronic ${ }^{87} \mathrm{Sr} /{ }^{66} \mathrm{Sr}$ initial ratios are a clue to the $\mathrm{Sr}$ evolution stage at the site of magma generation, and can evaluate the relative crustal-mantle contributions. Cogenetic granitoids, generated from isotopically homogeneous sources, show identical initial ratios; isochronic ages should pinpoint the true emplacement age, since magma cooling is generally thought to be a fast geologic process. Neverthless, supposed cogenetic granitoid of ten present real variations in initial ratios, a behavior which probably can be explained by several petrogenetic processes (e.g., mixing of magmas, crystal separation from magma mushes during protracted crystallization, assimilation of country rocks). Some of the cited mechanisms can be simulated using several $\mathrm{Rb} / \mathrm{Sr}$ variation diagrams. Provided data dispersion is not linked to systematic errors of various kinds, it is clear thar "anomalous" $\mathrm{Rb} / \mathrm{Sr}$ data reflect the influence of the cited genetic mechanisms, and may thus become valuable tool for petrogenetic interpretations. $\mathrm{Rb} / \mathrm{Sr}$ data of selected Brazilian granitoid massifs show significant spread; a brief discussion of these and of the corresponding geological setting indicate that many discrepancies arise from analytical and/or interpretation errors, although it is clear that several ones are actually due to the influence of complications in the petrogenetic process, such as pointed out above.
\end{abstract}

INTRODUÇÄO Sistemas isotrópicos constituídos por elementos radioativos e radiogênicos são de grande utilidade em Geologia e Petrologia, quando fornecem tanto idades absolutas de formação de rochas ou de eventos significativos por elas sofridos, quanto indicações de caráter genético e evolutivo. Entre os vários sistemas desenvolvidos, o $\mathrm{Rb} / \mathrm{Sr}$ é dos mais conhecidos e de maior aplicação às rochas granitóides.

A razão inicial ou $\mathrm{RI},\left({ }^{87} \mathrm{Sr} /{ }^{86} \mathrm{Sr}\right)_{0}$ representa a relação entre as proporções dos isotópos de massa 87 e 86 do $\mathrm{Sr}$ dos magmas granitóides no momento de sua geração, sendo obtida diretamente a partir do método isocrônico de determinação de idades $\mathrm{Rb} / \mathrm{Sr}$. De um modo geral, reflete o grau de evolução dos isótopos de $\mathrm{Sr}$ dos materiais-fontes, tornando-se parâmetro indicativo das contribuições potenciais do manto ou crosta oceânica e de diversos segmentos da crosta continental na constituição das rochas granitóides. As variações observadas de RIs em amostras de granitóides co-genéticos podem ser correlacionadas a diversos fatores, que incluem de características pouco ou muito homogêneas da fonte à influência de diversos processos petrogenéticos ligados à formação, migração, colocação e cristalização dos magmas. A existência dessas variaçð̋es amplia sensivelmente as potencialidades do método; ao mesmo tempo porém, exige, diversos cuidados na interpretação dos dados radiométricos e das RIs. Cuidados adicionais são também necessários no tratamento de granitóides que tenham sido submetidos a fenômenos de tipo hidrotermal- meteórico, pois estes produzem modificaçð̃es significativas na distribuição do $\mathrm{Rb}$ e do $\mathrm{Sr}$ das rochas afetadas.

No contexto brasileiro, os dados geocronológicos $\mathrm{Rb} / \mathrm{Sr}$ em rochas granitóides são ainda escassos, tendo sido em grande parte originados no Centro de Pesquisas Geocronológicas do IG-USP em pesquisas visando à elucidação de evolução geológica regional. Por este motivo, no perfodo inicial de aplicação de metodologia, na década de 70 , as análises desenvolvidas estiveram voltadas de forma preferencial à determinação de idades, sendo escolhidas para tal fim as amostras mais adequadas para a obtenção de isócronas de referências regionais. De fato, como o objetivo essencial era 0 reconhecimento preliminar das principais províncias tectônicas do território brasileiro, não havia maior compromisso com a co-geneticidade das amostras, procurando-se uma cobertura eficiente do território, por uma distribuição de amostragem propositadamente espalhada. Na década atual, face ao conhecimento adquirido do posicionamento das províncias tectônicas pré-cambrianas e face à disposição de dados geológicos, petrográficos e geoquímicos mais completos para alguns complexos ou maciços granitóides [Morungaba(SP), Jamon (PA) e São Sepé RS)], os trabalhos efetuados ou em andamento têm-se preocupado com dados isotópicos de maior detalhe. Configura-se, então, ocasião oportuna para a apresentação desta síntese, que tem por objetivo reunir alguns dos principais conceitos básicos relacionados ao método, em sua maioria já estabelecidos, suas aplicações e limitaçðes, para que a comunidade geológica brasileira seja alertada e ao mesmo tempo esclarecida da problemática envolvida, de modo a levá-la em conta quando da interpretação de dados que incluam idades isocrônicas $\mathrm{Rb} / \mathrm{Sr}$ e dados de $\mathrm{RIs}$ em rochas granitóides.

A SISTEMATICA Rb/Sr E OS ISOTOPOS DE Sr As características de sistemática $\mathrm{Rb} / \mathrm{Sr}$ são bem conhecidas

* Departamento de Mineralogia e Petrologia, Instituto de Geociências - Universidade de São Paulo. Cx. Postal 20899, CEP 01000, São Paulo, SP, Brasil

** Departamento de Geologia Geral, Centro de Pesquisas Geocronologicas, Instituto de Geociencias - Universidade de São Paulo. Cx. Postal 20899, CEP 01000, São Paulo, SP, Brasil 
(Faure \& Powell 1972, Faure 1977, Cordani 1980). Nos materiais terrestres em geral e nas rochas granitóides em particular, $\mathrm{Rb}$ e $\mathrm{Sr}$ ocorrem em quantidades pequenas, $\mathrm{da}$ ordem de dezenas a centenas de ppm, acompanhando o $\mathrm{Ke}$ - Ca, respectivamente, elementos com os quais apresentam melhores afinidades geoquímicas. Nos granitóides, o Sr concentra-se essencialmente nos feldspatos, nos quais ocupa as posições M pelas substituições $\mathrm{Ca} \rightleftharpoons \mathrm{Sr}$ em plagioclásios e $\mathrm{K}+\mathrm{Si} \rightleftharpoons \mathrm{Sr}+\mathrm{Al}$ em feldspatos potássicos. Substitui ainda o $\mathrm{Ca}$ em minerais acidentais ou acessorios, em especial hornblendas e apatitas. $\mathrm{O} \mathrm{Rb}$ é acumulado caracteristicamente nas micas e nos feldspatos alcalinos, intercambiando-se com oK.

${ }^{88} \mathrm{Sr},{ }^{86} \mathrm{Sr},{ }^{87} \mathrm{Sr}$ e ${ }^{84} \mathrm{Sr}$ são, em ordem de abundância, os quatro isótopos naturais e estáveis do elemento $\mathrm{Sr}$, e, destes, apenas o isótopo 87 é de origem radiogênica, formado pelo decaimento radioativo (emissão $\beta$ ) de átomos de ${ }^{87} \mathrm{Rb}\left(\lambda=1,42.10^{-11}\right.$ anos., Steiger \& Jager 1978).

A composição isotópica do Sr nos materiais, notadamente as razōes isotópicas em que intervém o isótopo 87 , é variável e depende tanto das concenttaçóes de $\mathrm{Rb}$ presentes nos sistemas estudados bem como de sua idade. Para os isótopos não-radiogênicos, valem as razס̋es ${ }^{86} \mathrm{Sr} /{ }^{88} \mathrm{Sr}=$ $0,1194 e^{84} \mathrm{Sr}^{88} \mathrm{Sr}=0,0068$ (Faure 1977). A razão ${ }^{87} \mathrm{Sr} /{ }^{86} \mathrm{Sr}$ é a que tem sido usada para caracterizar a componente radiogênica do $\mathrm{Sr}$. Em um sistema rochoso ou mineral, homogêneo e fechado durante o tempo $t$, ela depende do valor inicial efetivo $\left({ }^{87} \mathrm{Sr} /{ }^{86} \mathrm{Sr}\right)_{0}$, quando $t=0(=\mathrm{RI})$, da razão $\mathrm{Rb} / \mathrm{Sr}$ do sistema, e de $t$, podendo ser descrita pela equação:

$\left({ }^{87} \mathrm{Sr} /{ }^{86} \mathrm{Sr}\right)_{t}=\left({ }^{87} \mathrm{Sr} /{ }^{86} \mathrm{Sr}\right)_{0}+\left({ }^{87} \mathrm{Rb} /{ }^{86} \mathrm{Sr}\right)_{t} \cdot\left(\mathrm{e}^{\lambda t}-1\right)$

Em determinações geocronológicas, $t$ é a variável procurada e pode ser obtida, para uma certa unidade litológica, analisando-se amostras geoquimicamente diferenciadas, representativas, de rocha total (Cordani 1980), que sejam co-genéticas no sentido de apresentar a mesma idade e a mesma RI. Para tais amostras, os diferentes pares $\left[\left({ }^{87} \mathrm{Rb} /{ }^{86} \mathrm{Sr}\right) t,\left({ }^{87} \mathrm{Sr} /{ }^{86} \mathrm{Sr}\right) t\right]$ obtidos analiticamente obedecem à equação (1) e definem uma reta (isócrona) em coordenadas $\left[{ }^{87} \mathrm{Rb} /{ }^{86} \mathrm{Sr},{ }^{87} \mathrm{Sr} /{ }^{86} \mathrm{Sr}\right]$, cujo coeficiente angular $(a)$ define a idade do conjunto de amostras segundo a relaçấo $a=\mathrm{e}^{\lambda t_{11}}$ (Fig. 1). Este é o método isocrônico de datação de minerais e rochas, como visualizou Nicolaysen (1961). A razão inicial do $\mathrm{Sr}$ é obtida diretamente por extrapolação gráfica da is 6 crona para $\left({ }^{87} \mathrm{Rb} /{ }^{86} \mathrm{Sr}\right)_{t}=0$, como decorrência natural do processo de cálculo das idades. Como ressalta a Fig. 1, as amostras mais convenientes para a obtenção de RIs são as de razão $\mathrm{Rb} / \mathrm{Sr}$ mais baixa, pois, para estas, os valores calculados dependem em menor grau da qualidade analítica da isócrona. Quando as idades já são conhecidas, ou por isócronas em materiais sincrônicos, ou por outros meios independentes, as RIs de determinadas amostras podem ser calculadas diretamente pela equação (1).

A evoluçáo isotópica do Sr no tempo goológico Além do ${ }^{87} \mathrm{Sr}$ formado a partir do decaimento radioativo do ${ }^{87} \mathrm{Rb}$ durante toda a história da Terra, nas interpretações relativas à evolução isotópica do $\mathrm{Sr}$ deve ser levado em conta $0^{87} \mathrm{Sr}$ primitivo, gerado durante os processos de nucleossíntese que culminaram com a formação dos elementos que consti-

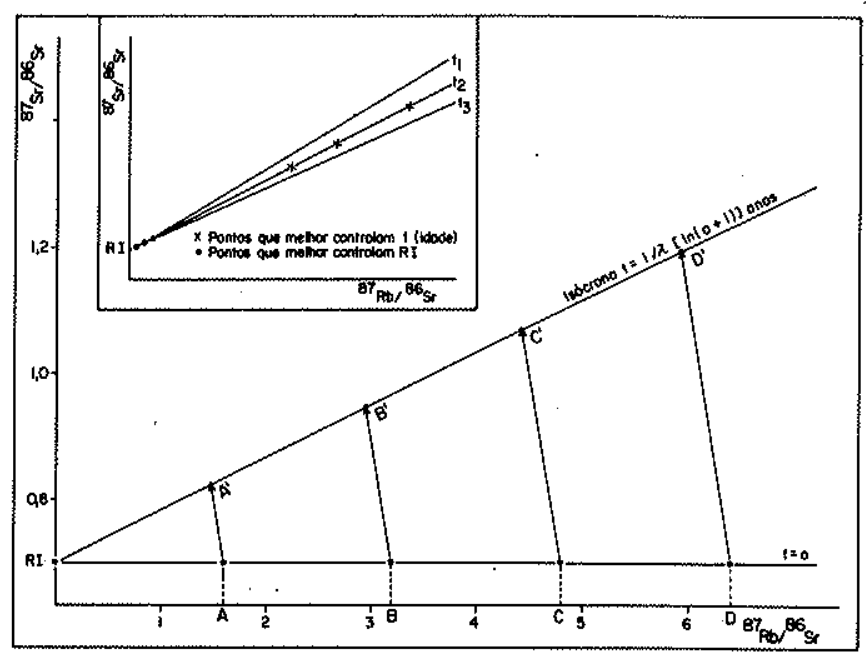

Figura 1 - Diagrama isocrônico $\mathrm{Rb} / \mathrm{Sr}$ hipotético (modelo de Faure \& Powell 1972). Amostras co-genéticas potenciais, com a mesma $R I$ são representadas pelas razões ${ }^{87} R b /{ }^{86} \mathrm{Sr}$. Decorrido o tempo $\mathbf{t}$ a evolução isotópica das amostras (indicada pelos vetores) para $\mathbf{A}^{\prime}, \mathbf{B}^{\prime}, \mathbf{C}^{\prime} e \mathbf{D}^{\prime}$, em decorrência do incremento de ${ }^{87} \mathrm{Sr}$ e decremento de ${ }^{87} \mathrm{Rb}$, define a isócrona $\mathbf{t}=1 / \lambda[\ln (a+1)]$, em que a é seu coeficiente angular. $A R I$ do conjunto amostral corresponde à interseçāo da isócrona com o eixo ${ }^{87} \mathrm{Sr} /{ }^{86} \mathrm{Sr}$ (i.e.e, ${ }^{87} \mathrm{Rb} /{ }^{86} \mathrm{Sr}=0$ ). No destaque, ressalta-se a menor dependência das RIs, em relaçäo à idade, para as amostras de razões ${ }^{87} \mathrm{Rb} /{ }^{86} \mathrm{Sr}$ mais baixas

tuem o sistema solar. As medidas diretas das razões ${ }^{87} \mathrm{Sr} /{ }^{86} \mathrm{Sr}$ em meteoritos e os cálculos decorrentes conduziram ao valor que seria representativo da composição isotópica do Sr na época em que se processaram os eventos de aglutinação de matéria, responsáveis pela formação da Terra, do Sol e dos demais objetos planetários do nossos sistema. Adota-se para a razão ${ }^{87} \mathrm{Sr} /{ }^{86} \mathrm{Sr}$ primordial o valor $0,69899 \pm 0,0005$ obtido na isócrona referente aos meteoritos basálticos acondríticos (BABI), com idade de 4,6 40,1 $\mathrm{Ga}$ (Papanastassiou \& Wasserburg 1969).

Rochas vulcânicas recentes, derivadas do manto terrestre, apresentam valores de RIs entre 0,702 e 0,703 (MORB) e entre 0,703 e 0,706 (OIB), cf. Faure (1977) e Cox et al. (1979). Se se considerar que as razões $\mathrm{Rb} / \mathrm{Sr}$ do manto não sofreram modificações de grande monta, o que é mera aproximação, entretanto, frente ao processo unidirecional de diferenciação manto $\rightarrow$ crosta - que ocorre com intensidade variável e mal-conhecida durante todo o tempo geológico - obteremos valores $(\mathrm{Rb} / \mathrm{Sr})_{\mathrm{m}}$ de $\sim 0,018 \mathrm{e} \mathrm{de} \sim$ 0,028 para as fontes MORB e OIB, respectivamente, os quais resultam nas variações lineares $\mathrm{de}^{87} \mathrm{Sr} /{ }^{86} \mathrm{Sr}$ apresentadas na figura 2.

A evolução dos isótopos de $\mathrm{Sr}$ na crosta continental é muito complexa e com enormes variações porque os elementos implicados ( $\mathrm{Rb}$ e $\mathrm{Sr}$ ) passam a participar ativamente do ciclo das rochas, onde têm comportamentos muito diferenciados, fato que culmina com a existência de inúmeros reservatórios com idades e/ou composições próprias e distintas. Contudo, devido à maior incompatibilidade do $\mathbf{R b}$ nos minerais mantélicos, o sial juvenil extraído do manto apresenta razões $(\mathrm{Rb} / \mathrm{Sr}) \mathrm{m}$ bem superiores às do material precursor, o que causa uma taxa de crescimento de Sr radio- 
gênico muito mais acentuada na crosta continental. Apenas minerais da crosta inferior poderiam apresentar razões $\mathrm{Rb} / \mathrm{Sr}$, em parte comparáveis às do manto superior contemporâneo, em decorrência do empobrecimento acentuado em $\mathrm{Rb}$ em favor da crosta superior, desde que sejam considerados válidos e atuantes durante o tempo geológico os processos irreversíveis de diferenciação geoquímica, os quais produziriam uma estratificação vertical na crosta continen. tal, com uma parte inferior granulítica, empobrecida em $\mathrm{Rb}$ e de caráter residual em relação a uma crosta superior granítica enriquecida em Rb (Moorbath \& Taylor 1981, Allègre et al 1983).

Taylor (1964) estima um valor $(\mathrm{Rb} / \mathrm{Sr})_{m}=0,24$ para a crosta continental; contudo, análises de razões $\left({ }^{87} \mathrm{Sr} /{ }^{8} \mathrm{Sr}\right)_{m}$ atuais de áreas cratônicas pré-cambrianas resultam em valores próximos a 0,718 (Faure \& Powell 1972). Admitindo-se que a idade média da crosta continental se aproxima de $2,5 \mathrm{Ga}$ (Faure \& Powell 1972, Allègre et al. 1983), podemos considerar o valor $(\mathrm{Rb} / \mathrm{Sr})_{m} \cong 0,18$ como uma aproximação razóavel para o valor crustal médio (Fig. 2). Cabe assinalar, no entanto, que este valor está sujeito a revisão na medida em que forem confirmadas para outras áreas da crosta continental idades médias inferiores ao valor referido, como parece ser o caso da Austrália, segundo os trabalhos recentes de McCulloch \& Hensel (1984) e Page et al. (1984), que envolvem interpretações embasadas na evolução isotópica do $\mathrm{Nd}$.

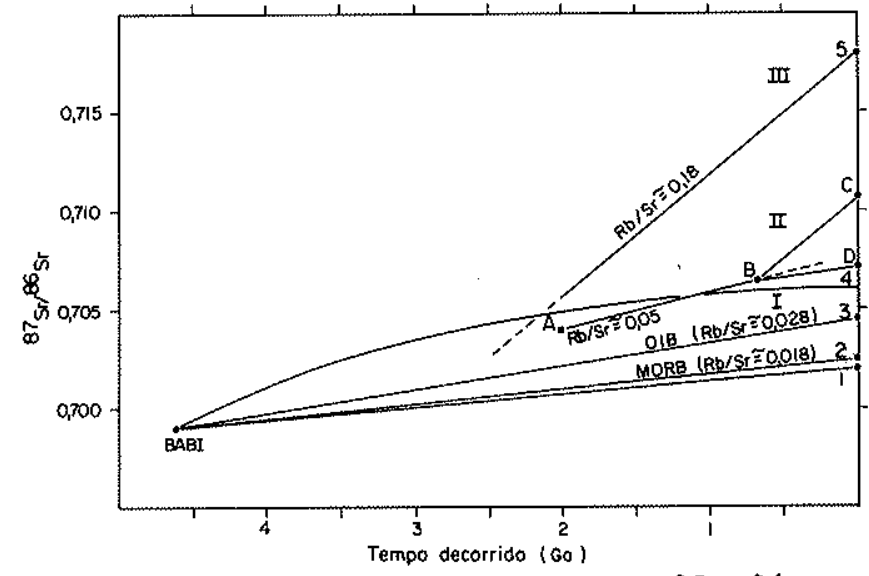

Figura 2 - Diagrama de evolução das razões ${ }^{87} \mathrm{Sr} /{ }^{86} \mathrm{Sr}$ no tempo geológico (modelo de Faure 1977), por simplicidade subdividido nos campos "basáltico" (I), "crustal intermediário" (II) e "crustal antigo" (III). Apresentam-se diversas trajetórias evolutivas possiveis para vários reservatorios: manto empobrecimento em elementos compativeis, com $R b / S r=c t e=0,015(1) ;$ fontes $M O R B$ com $R b / S r=c t e=$ $0,018(2)$; fontes $O I B$ com $R b / S r=c t e=0,028(3)$; fontes OIB férteis com $\mathrm{Rb} / \mathrm{Sr}$ variável, diminuindo progressivamente em direção às épocas mais recentes (4); e crosta continental granitica-granodioritica, extraida do manto há 2,5 $\mathrm{Ga}$ com $R b / S r=0,18(5)$. Estes últimos valores são considerados médias representativas da evolução da crosta continental da Terra. AB, BC $e$ BD são trajetórias de materiais extraidos do manto há $2,0 \mathrm{Ga}(\mathrm{com} \mathrm{Rb} / \mathrm{Sr}=0,05)$ e, posteriormente ( $h a \dot{a} \sim 0,65 \mathrm{Ga}$ ), submetidos à fusäo parcial ( $\mathbf{B C}$ = evolução das rochas formadas a partir dos magmas produzidos, com $\mathrm{Rb} / \mathrm{Sr}=0,18$ e $\mathbf{B D}=$ evolução do material restitico, com $R b / S r=0,028) . M O R B=b a s a l t o s$ das dorsais oceânicas; $O I B=$ basaltos das ilhas oceânicas
Essas variações isotópicas são muito significativas e permitem em diversos casos determinar se $o(s)$ material(ais)fonte(s) dos magma granitóides é(são) proveniente(s) de sistemas pertencentes à crosta continental ou ao manto/crosta oceânica. Fica de certa forma claro que granitóides com RIs no "campo basáltico" (Fig. 2) resultam de magmas derivados com grande probabilidade de reservatórios do manto da crosta oceânica ou ainda de sistemas com curta residência na crosta continental (por exemplo, materiais underplated, derivados diretamente do manto, ou materiais de prov'́ncias crustais "jovens", adicionados aos continentes mediante outros processos de acreção-diferenciação manto $\rightarrow$ crosta, tendo estes fenômenos ocorrido pouco antes dos episódios de extração dos magmas considerados).

Por outro lado, a fusão anatética de metassedimentos deve resultar em granitóides cujas RIs se situam nos campos crustal antigo ou crustal intermediário, na dependência das características geoquímicas, isotópicas e das idades dos materiais envolvidos. As RIs mais próximas à interface manto/ crosta continental são de interpretação mais complexa e podem ser representativas de reservatórios da crosta continental (por exemplo rochas infracrustais granulíticas, rochas supracrustais vulcanoclásticas relativamente jovens) ou de manto anômalo (por exemplo, fontes no manto inferior mais primitivo, fontes "enriquecidas" de elementos incompatíveis). Tais valores, intermediários, estão também associados a processos mais complicados, que envolvem mistura de materiais com participação do manto e/ou crosta oceânica e/ou segmentos variados da crosta continental em diferentes proporções, e parece ser este o caso de grande parte dos granitóides que constituem os maiores batólitos conhecidos. Alguns desses processos serão comentados pos. teriormente.

\section{CARACTERISTICAS ISOTOPICAS DOS GRANITOIDES} NO CONTEXTO GLOBAL COmo já salientou Read (1957), granitóides são rochas com espectro composicional e estrutural muito amplo, e isto se deve ao fato de não serem repetidas exatamente as mesmas condições genético-evolutivas. Por outro lado, parece ser possível diferenciar, por meio de critérios geológicos, petrográficos e geoquímicos, associações granitóides "tipo" relacionadas a contextos e ambientes geotectônicos próprios e característicos, os quais se encontram bem marcados nos sistemas tectônicos fanerozóicos. Tais associações são ligadas ao desenvolvimento de cadeias e arcos insulares oceânicos, margens continentais ativas, zonas de colisão continental, cinturões de cisalhamento ou, ainda, às reativações de regiões cratônicas (Zwart 1967, Lameyre \& Bowden 1982, Pitcher 1983, White \& Chappell 1983, Pearce et al. 1984).

A cada ambiente correspondem condições próprias de gênese, migração e colocação dos magmas granitóides. No primeiro aspecto, as RIs ressaltam as diferenças geoquímicas e de idades entre os potenciais materiais-fontes. Na tabela 1 , encontram-se compiladas algumas informações gerais disponíveis na literatura, com destaque para os ambientes geológicos de acordo com os conceitos da tectônica de placas, as fontes potenciais e as razões iniciais mais típicas dos granitóides presentes em cada caso. Para fins de classificação das "aşsociações-tipos", optou-se pela proposta de Pitcher (1983), muito útil em termos descritivos, embora não aceita universalmente (Didier et al. 1982); é desne- 
cessário lembrar também que sínteses como a colocada são apenas aproximações das situações naturais.

A observação desta tabela demosntra que existe certo recobrimento entre os intervalos de RIs nas várias tipologias de granitóides relacionadas, não sendo o valor da RI, por si só, um parâmetro diagnóstico inequvoco para sua caracterização. Por outro lado, ressalta as diferenças mais marcantes (como seria de esperarl) entre os granitóides associados a processos de subducção de litosfera oceânica, e os derivados de processos de colisão e/ou cisalhamento continental, o que reafirma desta forma o contraste entre os ambientes em que predomina o retrabalhamento de materiais crustais mais antigos (com domínio de granitóides $\mathrm{S}, \mathrm{I}$ Caledoniano), em oposição àqueles onde domina a acreção, direta ou indireta, de materiais mantélicos à crosta continental (em especial granitóides $\mathrm{M}$ ). As razões iniciais mais elevadas dos granitóides I Cordilheiranos, em relaçōa ao tipo M, refletiriam, segundo diversos autores, a incidência de contribuição crustal, em graus variáveis nos materiais derivados do manto e/ou crosta oceânica, fato que encontraria certo apoio na zoneografia observada em alguns desses terrenos, com os valores de RIs aumentando em direção ao continente, portanto em direção ao espessamento da crosta siálica. Outras interpretações sugerem, contudo, contribuições essenciais que do manto/crosta oceânica, quer de materiais básico-intermediários underplated na crosta continental (ver, entre outros, Hurley et al. 1965, Brown 1977, Pitcher 1983 e Wyllie 1984).

Os granitóides de tipo I Caledoniano apresentam valores de RIs intermediários entre os tipo I Cordilheirano e $S$, que sugere contribuições de materiais crustais variados e também do manto, fato reforçado por sua associação ocasional com magmatismo básico. De fato, na área-tipo dessas rochas, Harmon et al. (1984) concluem, mediante estudos geoquímicos e isotópicos, que pode existir participação de diversos segmentos crustais e do manto, com predomínio acentuado dos primeiros. Finalmente, granitóides anorogênicos "A" apresentam RIs muito variáveis, que cobrem todos os intervalos mais característicos dos demais tipos, o que indicaria diferentes contribuições de fontes mantélicas ou crustais (ver Bonin 1982).

A visão conjunta dos dados apresentados na figura 3 mostra, graficamente, $o$ aumento das RIs dentro das séries cálcio-alcalinas, no sentido $\mathrm{M} \rightarrow$ I Cordilheirano $\rightarrow$ I Caledoniano $\rightarrow \mathrm{S}$, caracterizando, nesta ordem, contribuições cada vez mais efetivas de materiais mais evoluídos isotopicamente. Por outro lado, a presença de superposição entre as RIs das "associações-tipos" implica a necessidade de dados adicionais, de tipo geológico, petrográfico e geoquímico, para estudos petrogenéticos visando a caracterização e a classificação tectônica das associações granitóides, pois não existem limites naturais fixos entre as diversas associações como definidas do ponto de vista isotópico.

\section{VARIAÇOEES ISOTÓPICAS EM GRANITOIDES CO- -GENÉTICOS Nos itens precedentes foram abordadas} as variaçðes das razões iniciais $\left({ }^{87} \mathrm{Sr} /{ }^{86} \mathrm{Sr}\right) 0$ nos reservatórios geoquimicos maiores, na escala do planeta (sistemas mantélicos e crustais) bem como nos principais ambientes tectônicos em que ocorre formação de granitóides em grande escala. As variações foram comentadas de modo genérico, levando-se em conta apenas o possível balanço geoquímico do $\mathrm{Rb}$ e do Sr entre os sistemas químicos referidos. Neste item procura-se caracterizar as variações de escala menor relacionadas com o próprio espectro composicional apresentado pela grande maioria das associaçōes granitóides co-genéticas, particularmente as expandidas. Estas variações, que se expressam em escalas decimétricas a quilomé-

Tabela I - Caracteristicas isotópicas do Sr, fontes potenciais e dados petrográficos das associações "tipo" dos sistemas tectônicos do Fanerozóico (adaptado de Pitcher 1983, Harmon et al. 1984, Pearce et al. 1984)

\begin{tabular}{|c|c|c|c|c|}
\hline Ambiente geológico & "Associação tipo" & Variedades Petrográficas & Fontes Potenciais & $\begin{array}{l}\text { Razões lniciais } \\
\left(^{87} \mathrm{Sr} /{ }^{86} \mathrm{Sr}\right) 0\end{array}$ \\
\hline $\begin{array}{l}\text { Cadeias e arcos insulares oceâ- } \\
\text { nicos. Tectônica horizontal, } \\
\text { compressional e tensional. }\end{array}$ & $M$ & $\begin{array}{l}\text { Gabros, dioritos e tonalitos/ } \\
\text { trondjemitos. Meta- a pouco } \\
\text { peraluminosos (termos mais } \\
\text { félsicos). }\end{array}$ & $\begin{array}{l}\text { Manto, crosta oceânica. Em } \\
\text { parte, sedimentos marinhos e } \\
\text { vulcanoclásticos. }\end{array}$ & $\begin{array}{l}\text { Inferios a } 0,704 \text { (em geral en- } \\
\text { tre } 0,702 \text { e } 0,703 \text { ) }\end{array}$ \\
\hline $\begin{array}{l}\text { Margens continentais ativas (ti- } \\
\text { po Andino). Tectônica verti- } \\
\text { cal, compressional a tensional. }\end{array}$ & $\frac{I}{(\text { Cordilheirano) }}$ & $\begin{array}{l}\text { Série contínua "expandida" } \\
\text { de dioritos (gabros) a monzo- } \\
\text { granitos, com predomínio de } \\
\text { tonalitos. Meta- a pouco pera- } \\
\text { luminosos (termos mais félsi- } \\
\text { cos). }\end{array}$ & $\begin{array}{l}\text { Manto, crosta oceânica. Em } \\
\text { teriais siálicos infracrustais; em } \\
\text { parte sedimentos clásticos e } \\
\text { vulcanoclásticos. }\end{array}$ & $\begin{array}{l}\text { Entre } 0,703 \text { e } 0,708 \text { (em geral } \\
\text { inferior a } 0,706) \text {. }\end{array}$ \\
\hline $\begin{array}{l}\text { Colisão, continental(tipo Her- } \\
\text { cínico), sin- a tardi-colisão. } \\
\text { Cinturöes de cisalhamento. } \\
\text { Tectônica horizontal, predo- } \\
\text { minantemente compressional. }\end{array}$ & $S$ & $\begin{array}{l}\text { Predominam monzo- e sieno- } \\
\text { granitos leuco- a hololeuco- } \\
\text { cráticos, aluminosos e forte- } \\
\text { mente peraluminosos. }\end{array}$ & $\begin{array}{l}\text { Supracrustais metassedimenta- } \\
\text { res, em geral com alguma con- } \\
\text { tribuiçäo meta-'gnea. }\end{array}$ & $\begin{array}{l}\text { Superior a } 0,708 \text { (em geral en- } \\
\text { tre } 0,710 \text { e } 0,720 \text { ). }\end{array}$ \\
\hline $\begin{array}{l}\text { Colisão continental (tipo Ca- } \\
\text { ledoniano), tardj- a pós-colir } \\
\text { săo. Tectônica vertical, predo- } \\
\text { minantemenet tensional. }\end{array}$ & $\begin{array}{c}I \\
\text { (Caledoniano) }\end{array}$ & $\begin{array}{l}\text { Predominam granodioritos e } \\
\text { monzogranitos leuco- a holo- } \\
\text { leucocráticos, meta* a pouco, } \\
\text { peraluminosos. Possível as- } \\
\text { sociação descontínua com mag- } \\
\text { matismo básico. }\end{array}$ & $\begin{array}{l}\text { Materiais siálicos infracustais, } \\
\text { em geral de origem ígnea. Em } \\
\text { parte, manto; em parte, algu- } \\
\text { ma contribuição supracrustal. }\end{array}$ & Em geral entre 0,705 e 0,709 . \\
\hline $\begin{array}{l}\text { Cratonização (Magmatismo ter- } \\
\text { minal). Reativação de áreas } \\
\text { cratónicas (Magmatismo ano- } \\
\text { rogênico). }\end{array}$ & $A$ & $\begin{array}{l}\text { Monzon, sieno- e álcali" fel- } \\
\text { dspato-granitos leuco- a holo- } \\
\text { leucocráticos, meta- a peralu- } \\
\text { minosos e peralcalinos. Pos- } \\
\text { sível associação descontínua } \\
\text { com magmatismo básico. }\end{array}$ & $\begin{array}{l}\text { Manto litosférico subcrustal, } \\
\text { incluindo quase sempre con- } \\
\text { tribuiçōes infracrustais e, pos- } \\
\text { sivelmente, supracrustais. }\end{array}$ & Em geral entre 0,702 a 0,712 . \\
\hline
\end{tabular}


tricas, podem ser explicadas pelos diferentes processos petrogenéticos envolvidos na formação de batólitos granitóides, os quais incluem de cristalização fracionada a partir do mesmo magma parental a processos de fusão fracionada, desmistura de mushes, mistura de magmas, assimilação de rochas encaixantes etc. Diversos desses mecanismos podem contribuir para a existência de variações isotópicas significativas durante o próprio evento de formação das rochas, de forma a invalidar, em parte, as premissas para a construção de isócronas. Evidentemente, este fato impõe restriçб̄es às interpretações mais imediatas e implica a necessidade de conhecimentos geológicos mais adequados, os quais permitam uma melhor seleção de amostras para análise em função da ocorrência ou não de distintos níveis de homogeneização isotópica e interpretações mais elaboradas de diagramas iso. crônicos.

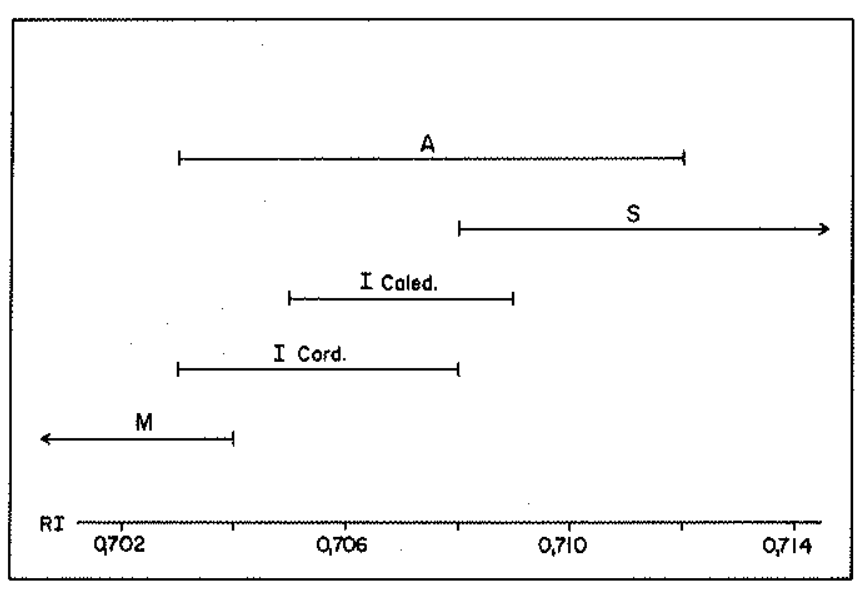

Figura 3 - Intervalos de razões iniciais mais caracteristicos das associafỗes granitóides - "tipo" com idades fanerozóicas (dados coligidos principalmente de Pitcher 1983) e Harmon et al. 1984, cf. Tab. 1)

A importância das características da rocha-fonte Para condições físico-químicas "externas" semelhantes, as características dos magmas granitóides extraídos dependem exclusivamente das características dos materiais-fontes. Do ponto de vista da sistemática $\mathrm{Rb} / \mathrm{Sr}$, importa principalmente considerar as possíveis distribuiçōes das razð̄es ${ }^{8} \cdot{ }^{7} \mathrm{Sr} /{ }^{86} \mathrm{Sr}$. Para magmas derivados de reservatórios intrinsicamente homogn̂eos no tocante às razões ${ }^{87} \mathrm{Sr} /{ }^{86} \mathrm{Sr}, \mathrm{co}$ mo, por exemplo, no caso de magmatismo mantélico, o magma originado estará em equilíbrio isotópico desde a sua origem e, se não for afetado posteriormente, as rochas granitóides resultantes deverão apresentar isócronas de qualidade excelente com amostras essencialmente co-lineares. Equilóbrio isotópico também é alcançado a partir de fontes heterogêneas, que dependem das características do processo responsável pela geração de magmas; por exemplo, magmas granitóides derivados de graus elevados de fusão parcial relativamente prolongada, em ambiente rico em voláteis, devem resultar muito homogêneos.

Por outro lado, nos casos de fontes heterogêneas e de processos formadores de magmas que não conseguem conduzir à homogeneização completa dos materiais, a evolução das razões ${ }^{87} \mathrm{Sr} /{ }^{86} \mathrm{Sr}$ nos diferentes subsistemas químicos resultantes obedecerá à Equação (1) e após o tempo $t, 0$ magma granítico ou o conjunto de rochas resultantes de sua cristalização apresentará variaçס̄es nas razס̃es isotópicas de acordo com a distribuição das razões $\mathrm{Rb} / \mathrm{Sr}$ da fonte original (ver discussões adicionais em Roddick \& Compston 1977 e itens subseqüentes). Se as dimensōes dos segmentos-fontes com razões $\mathrm{Rb} / \mathrm{Sr}$ distintas forem consideráveis em relação às das áreas sujeitas à fusão, podem ser gerados corpos ou suítes com diferentes RIs. De fato, esta é uma das bases para cálculos tentativos de idade dos materiais-fontes (Compston \& Chappell 1979). De forma análoga, devemos esperar que a produção episódica de magmas a partir de fontes heterogêneas deste tipo resulte em RIs variáveis, visto que os líquidos resultantes de extraçōes sucessivas variam na dependência do quimismo global dos materiais-fontes $\mathrm{e}$, em especial, tais variações são acompanhadas por mudanças relevantes nas razőes $\mathrm{Rb} / \mathrm{Sr}$ tanto dos magmas, como do material residual.

\section{Cristalização de suítes granitóides co-magmáticas: um caso} ideal Consideremos um pulso magmático granitóide que seja essencialmente líquido e homogêneo e se mantenha como um sistema fechado durante sua ascenção, colocação e cristalização. Neste caso, as variações composicionais resultantes serão ditadas unicamente pelos princípios de equilíbrio cristal/líquido. Devido, de uma forma genérica, à maior preferência relativa do $\mathrm{Rb}$ em permanecer no líquido, as razões $\mathrm{Rb} / \mathrm{Sr}$ aumentam de maneira acentuada nos dife renciados progressivamente mais félsicos. Para um modelo simples de cristalização fracionada contínua (Lei de Rayleigh), podemos obter as razões $\mathrm{Rb} / \mathrm{Sr}$ instantâneas dos sucessivos sólidos formados aplicando-se a seguinte equação, rearranjada de Allègre \& Minster (1978):

$$
(\mathrm{Rb} / \mathrm{Sr})_{\mathrm{S}}=(\mathrm{Rb} / \mathrm{Sr})_{i} \cdot\left(D^{\mathrm{Rb}} / D^{\mathrm{Sr}}\right) \cdot F\left(D^{\mathrm{Rb}}-D^{\mathrm{Sr}}\right)
$$

em que os índices $s$ e $i$ indicam as quantidades presentes nos sólidos formados a cada estágio e no magma inicial, respectivamente; $F$ a fração de líquido residual em cada estágio; e $D$, o coeficiente de partição total cristal/liquido (Fig. 4). Deste modo, explica-se facilmente, embora de forma algo simplória, a existência de amostras com valores diferenciados e próprios para as razóes $\mathrm{Rb} / \mathrm{Sr}$, mesmo para granitóides com aspecto homogêneo.

$O$ caso apresentado corresponde à situação ideal para a aplicação da sistemática $\mathrm{Rb} / \mathrm{Sr}$. A amostragem representativa, aleatória, de diferentes partes dos corpos assim constituídos permitem a determinação precisa da idade de cristalização e, conseqüentemente, da RI, a qual representa o valor ${ }^{87} \mathrm{Sr} /{ }^{86} \mathrm{Sr}$ do líquido ao se iniciarem os processos de cristalização.

Por outro lado, se o intervalo de cristalização do magma for muito longo (por exemplo da ordem de 10 a $20 \mathrm{Ma}$ ), o incremento nas razōes ${ }^{87} \mathrm{Sr} /{ }^{86} \mathrm{Sr}$ dos sucessivos líquidos residuaỉs em relação ao valor do magma inicial será significativo, fato que, aliado às variações $\mathrm{Rb} / \mathrm{Sr}$, poderá resultar em dados anomalos. McCarthy e Cawthorn (1978) apresentam um modelo teórico de cristalização fracionada lenta e demonstram que as rochas formadas precocemente apresentarão idades mais antigas e RIs mais baixas enquanto as rochas mais evoluídas resultarão em idades mais novas e RIs mais altas em relação aos valores reais da colocação dos magmas, porque, nos diagramas isocrônicos $\mathrm{Rb} / \mathrm{Sr}$, as amostras definem uma linha convexa. Líquidos "congelados" 


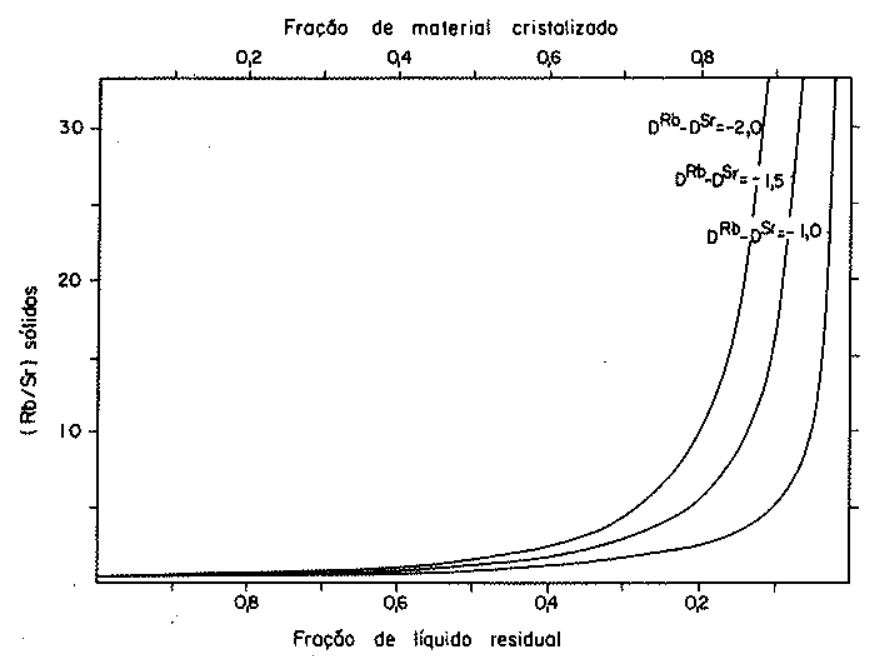

Figura 4 - Variaçāo das razões $R b / S r$ nos sólidos separados instantaneamente por cristalização fracionada (modelo de Rayleigh) de um magma com razão inicial $R b / S r=2,0, \mathrm{em}$ função das frações de liquidos residuais e de materiais cristalizados, para alguns valores de $D^{R} b-D S r$ (diferenca entre os coeficientes de partição totais do $R b$ e do $S r$ )

(por exemplo aplitos) apresentariam sempre idades mais novas e RIs mais elevadas. Assim, os resultados obtidos em uma suíte com este comportamento dependeriam significativamente das amostras selecionadas para a análise.

$O$ intervalo de tempo de cristalização de um magma, necessário para que as variações colocadas sejam significativas, parece exageradamente extenso; contudo, mesmo pa. ra intervalos mais realísticos, as fases residuais, face a seu extremo enriquecimento em $\mathrm{Rb} / \mathrm{Sr}$, poderão produzir pontos anômalos em diagramas isocrônicos, visto que representam, de fato, sistemas químicos algo mais jovens e com RIs mais elevadas que as do magma original. A figura 5 ilustra o incremento das razðes ${ }^{87} \mathrm{Sr} /{ }^{86} \mathrm{Sr}$ em sistemas fechados em função das razões $\mathrm{Rb} / \mathrm{Sr}$ para intervalos em tempo de 0,5 1,0 e 2,0 Ma; diagramas que consideram incrementos infinitesimais sucessivos podem ser obtidos em McCarthy \& Cawthorn (1978).

Granitóides co-genéticos relacionados a mecanismos de desmistura Em uma situação talvez mais realística que a anterior, parte-se de materiais-fontes de natureza crustal, não-homogêneos a respeito da distribuição dos isótopos de $\mathrm{Sr}$ e que sofreram parcela relativamente reduzida de fusão (20\%-30\%), suficiente apenas para que o mush granitóide assim formado se desprenda e inicie sua ascenção através da crosta siálica (Compston \& Chappell 1979). Um sistema como o citado só alcançaria condições de equilíbrio isótopico perfeito no caso de fusão em larga escala durante a migração do mush (por exemplo, ascenção adiabática) acompanhada de conveç̧ão vigorosa. Por outro lado, durante a ascenção/colocação, podem ocorrer processos de filtração por pressão que determinam a desmistura progressiva entre os líquidos e os sólidos da "massa" inicial (modelo "restítico" de. White \& Chappell 1977), e os granitóides resultantes apresentariam, então, variaçôes próprias do instante de sua individualização. Nestes casos, em função da distribuição das razões $\mathrm{Rb} / \mathrm{Sr}$ nos materiais-fontes e dos níveis de homogeneização das amostras selecionadas para

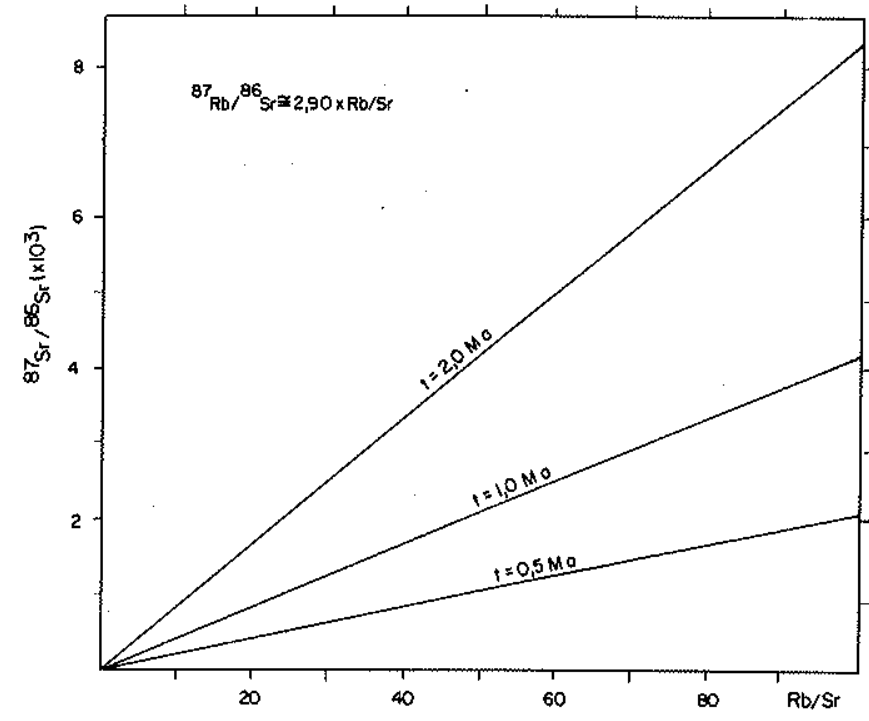

Figura 5 - Incrementos da razão ${ }^{87} \mathrm{Sr} /{ }^{86} \mathrm{Sr}$ em sistemas homogêneos e fechados, em dependência da razão $\mathrm{Rb} / \mathrm{Sr}$ do sistema, para alguns intervalos de tempo decorrido

análise, a sistemática isotópica da área fonte pode ser parcialmente preservada (Roddick \& Compston 1977, ver também Pankhurst 1979), como uma "memória" isotópica. Em diagramas isocrônicos, os dados isotópicos obtidos mostrar-se-iam anômalos com idades aparentes mais antigas que as de cristalização ou do evento intrusivo, em especial para os membros mais máficos da suíte, devido à presença, nestes, de maiores quantidades de materiais restíticos. Interpretações adequadas, caracterizando eventos relevantes, só poderão ser efetuadas após o reconhecimento dos domínios em que a homogeneização isotópica foi de fato completada, quando da formação das rochas (Roddick \& Compston 1977).

Granitóides co-genéticos relacionados a mecanismos de mistura e assimilação Variaçōes composicionais de suítes granitóides, particularmente das cálcionalcalinas "expandidas", podem resultar de processos de mistura de magmas gerados no manto superior/crosta oceânica com outros mag. mas derivados da crosta siálica (por indução dos primeiros) ou ainda de outros processos de hibridização infra-crustal (Wyllie 1984, Harmon et al. 1984). Além disso, magmas granitóides podem também conter contribuições significativas de materiais encaixantes incorporados durante as etapas de ascenção e/ou cristalização. Suítes granitóides co-genéticas deste tipo mostram, com freqüência, um incremento nas quantidades de $\mathrm{Sr}$ radiogênico em direção às rochas mais félsicas, fato sugestivo de contribuição progressiva de materiais crustais mais evoluídos.

Processos de mistura simples entre dois termos finais de composição fixa podem ser tratados com relativa facilidade por equações e construções gráficas binárias apropriadas. Se $A$ e $B$ são dois termos finais envolvidos em uma mistura progressiva ("mecânica") e $X$ representa o teor de um elemento ou óxido determinado em $A$ e $B$, a quantidade deste elemento ou óxido em quaisquer termos híbridos $(H)$ é apenas função de seus teores em $A$ e $B$ e do grau de mistura entre $A$ e $B$, ou seja: 


$$
X_{H}=X_{A} \cdot f+X_{B} \cdot(1-f)
$$

em que $f=A /(A+B)$ é a fração relativa ao termo $A$ na mistura final. Equações similares podem ser escritas também para isótopos de elementos e razões entre elementos, óxidos e isótopos.

Considerando-se agora duas variáveis $X$ e $Y$ deste tipo, e rearranjando as duas respectivas equações da forma (3), de modo a eliminar $f$, pode-se chegar a uma correlação direta entre essas variáveis, representada por uma reta (linha de mistura) em um gráfico de coordenadas $(X, Y)$, caso essas variáveis representem teores de elementos, isótopos de elementos ou óxidos (Faure 1977). Uma equação mais elegante para tais sistemas de mistura foi desenvolvida por Langmuir et al (1978), com a seguinte forma geral:

$$
\mathbf{a} X_{H}+\mathbf{b} X_{H} Y_{H}+\mathbf{c} Y_{H}+\mathbf{d}=0
$$

Nesta equação, o coeficiente $b$ é uma função dos denominadores das variáveis em questão. Quando $X$ e $Y$ são elementos, isótopos ou óxidos, ou ainda quando são razões entre elementos, isótopos ou óxidos que apresentem sempre os mesmos denominadores, $b=0$ e a Equação (4) é reduzida à forma linear. Quando $b \neq 0$ a Equação (4) representa uma hipérbole ou suas assindotas.

A respeito dos elementos e razões isotópicas que importam à sistemática em pauta, diagramas de mistura ${ }^{87} \mathrm{Sr} /{ }^{86} \mathrm{Sr}$ versus. $\mathrm{Sr}$, ou versus $\mathrm{Rb}$, resultam em funções hiperbólicas descritas pela Equação (4). Os coeficientes a, b, c e d são dados por Langmuir et al. (1978) ou podem ser obtidos algebricamente aplicando-se equações como a Equacão (3), cf. Faure (1977). Por outro lado, diagramas de tipo ${ }^{87} \mathrm{Sr} /{ }^{86} \mathrm{Sr}$ versus $1 / \mathrm{Sr}$ ou versus $\mathrm{Rb} / \mathrm{Sr}$, resultam em correlações lineares, cuja equação geral também pode ser escrita sob a forma:

$$
\begin{aligned}
& Y_{H}-Y_{B}=\begin{array}{l}
X_{H}-X_{B} \\
Y_{A}-Y_{B}
\end{array}=X_{A}-X_{B}
\end{aligned}
$$

em que $Y={ }^{87} \mathrm{Sr} /{ }^{86} \mathrm{Sr}$ e $X=1 / \mathrm{Sr}$ ou $\mathrm{Rb} / \mathrm{Sr}$. Este último caso é particularmente importante porque, em diagramas isocrônicos $\left({ }^{87} \mathrm{Rb} /{ }^{86} \mathrm{Sr}\right.$ versus $\left.{ }^{87} \mathrm{Sr} /{ }^{86} \mathrm{Sr}\right)$, os processos de mistura simples resultam em correlaçóes lineares sem qualquer significado temporal; são as denominadas isócronas fictícias, pseudo-isócronas ou ainda linhas de mistura (por exemplo, Faure 1977).

Alguns exemplos de aplicação desses diagramas, que contêm simulações para ilustrar os efeitos esperados, são colocados nas figuras $6 \mathrm{a}(\mathrm{RI} v \mathrm{~s}$. Rb), $6 \mathrm{~b}(\mathrm{RI} v \mathrm{~s}$. $\mathrm{Sr}$.), $6 c$ (RI vs. $1 / \mathrm{Sr})$ e $7\left(\mathrm{RI}\right.$ vs. $\left.{ }^{87} \mathrm{Rb} /{ }^{86} \mathrm{Sr}\right)$. Neste último diagrama ilustra-se, também, como os mecanismos de mistura podem produzir idades aparentes fictícias, mais velhas que as idades reais de cristalização das rochas granitóides (Vlach 1985). Para a construção dos diagramas, foram utilizados os seguintes termos finais: magma $B(\mathrm{Rb}=10 \mathrm{ppm}, \mathrm{Sr}=400$ ppm e $\left.{ }^{87} \mathrm{Sr} /{ }^{86} \mathrm{Sr}=0,703\right)$ e magma $A(\mathrm{Rb}=150 \mathrm{ppm}, \mathrm{Sr}=$ $200 \mathrm{ppm}) \mathrm{e}^{87} \mathrm{Sr} /{ }^{86} \mathrm{Sr}=0,707$ ), valores que podem ser tomados como representativos de magmas derivados no manto superior e na crosta inferior, respectivamente (De Paolo 1981, Compston \& Chappell 1979).
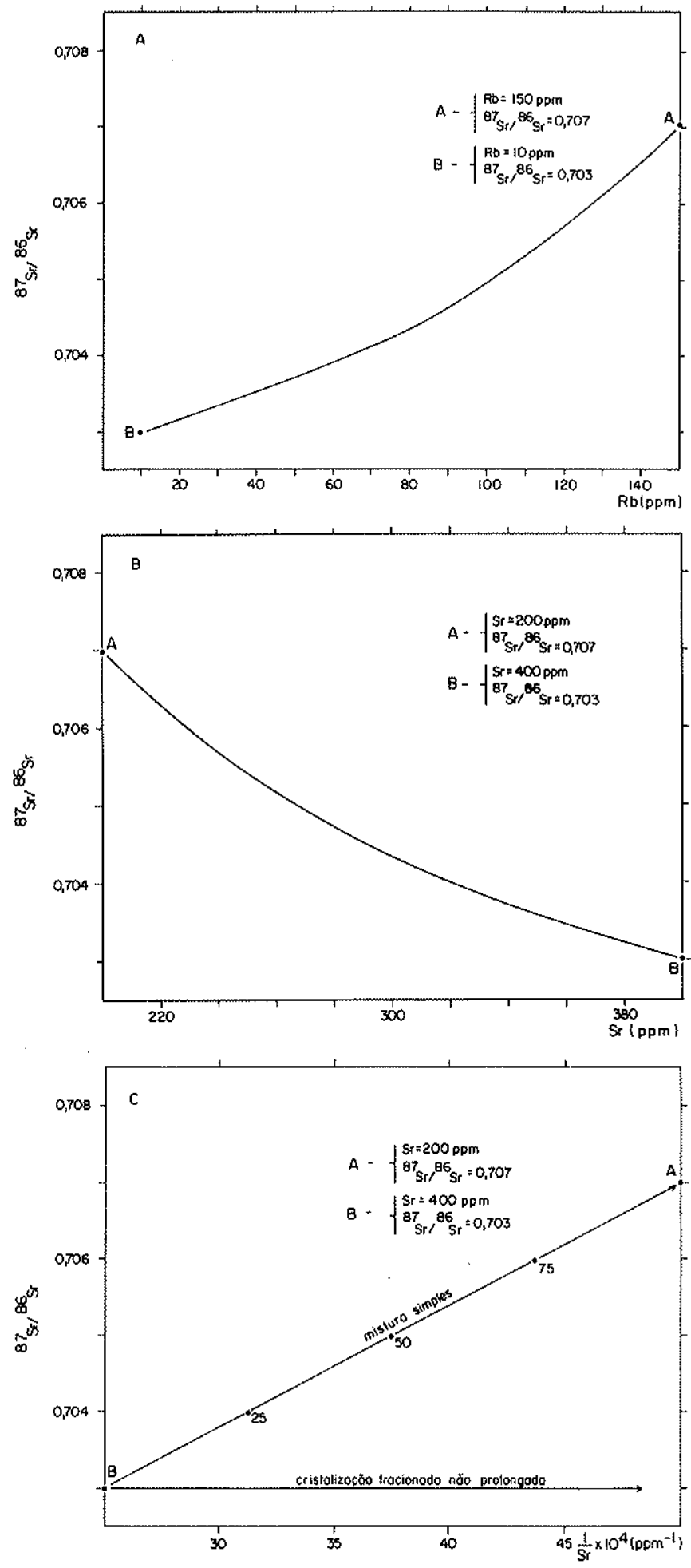

Figura 6 - Diagramas de variação simulados para mistura simples entre possiveis magmas derivados do manto (B) e da crosta inferior (A), envolvendo os elementos $R b, S r$ e a razão isotópica ${ }^{87} \mathrm{Sr} /{ }^{86} \mathrm{Sr}$ (ver texto): a ${ }^{87} \mathrm{Sr} /{ }^{86} \mathrm{Sr}$ vs. $\mathrm{Rb}$ $(A)$; b. ${ }^{87} S r /{ }^{86} S r$ vs. $S r(B)$ e c. ${ }^{87} S r /{ }^{86} S r$ vs. $1 / S r$. No último diagrama, compara-se a trajetória de mistura entre $\mathbf{B}$ $e$ A com a trajetória esperada quando o magma $\mathbf{B}$ evolui por cristalização fracionada; na primeira, estão representadas as quantidades relativas de $\mathrm{A}$ (em \%) para alguns dos termos hibridos 


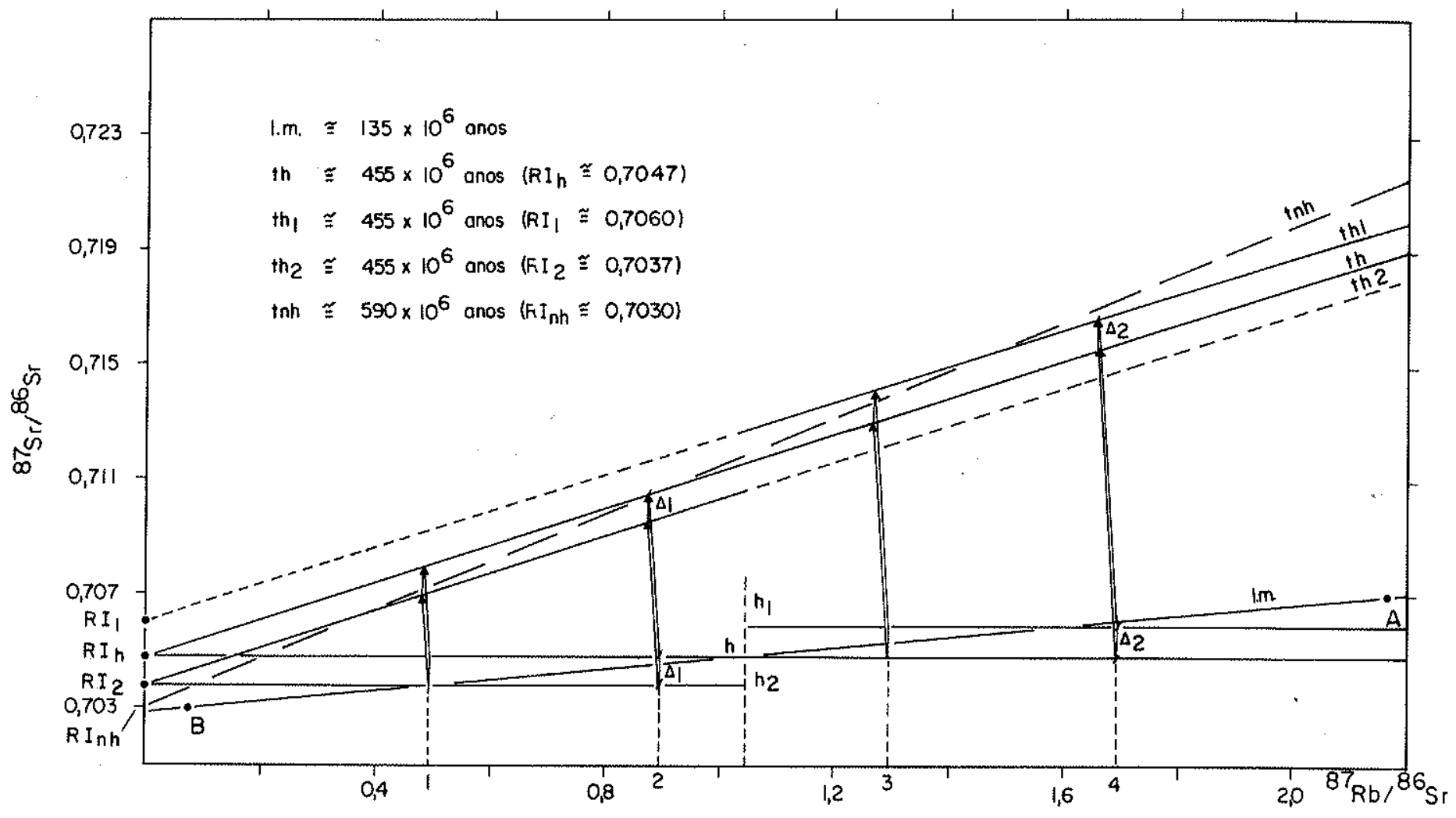

Figura 7 - Efeitos devidos à mistura simples em diagrama isocrônico hipotético para magmas A e $\mathrm{B}$ de caracteristicas iguais aos utilizados na Figura 6 (B: $R b=10 \mathrm{ppm}, \mathrm{Sr}=400 \mathrm{ppm} \mathrm{e}{ }^{87} \mathrm{Sr} /{ }^{86} \mathrm{Sr}=0,703 ; \mathrm{A}: \mathrm{Rb}=150 \mathrm{ppm}, \mathrm{Sr}=200$ ppm $\left.e^{87} \mathrm{Sr} /{ }^{86} \mathrm{Sr}=0,707\right)$, cf. Vlach (1985). A linha de mistura (l.m) possui coeficiente angular que define uma isócrona ficticia com $135 \mathrm{Ma}$. Supondo uma homogeneização isotópica completa após uma mistura com A/B $\stackrel{1}{=}$ (nivel $\mathrm{h})$, obtém-se a idade real de cristalização $\left(t_{\mathrm{h}}{ }_{1} \operatorname{com} R \mathrm{~h}_{\mathrm{h}} \cong\left[\left({ }^{87} \mathrm{Sr} /{ }^{86} \mathrm{Sr}\right)_{\mathrm{A}}+\left({ }^{8}{ }^{7} \mathrm{Sr} /{ }^{86} \mathrm{Sr}\right) \mathrm{B}\right] / 2\right.$. Por outro lado, se existe ho mogeneização parcial, em diferentes dominios (por exemplo, niveis $\mathrm{h}_{1} e \mathrm{~h}_{2}$ ), idades reais (por exemplo, $\mathrm{t}_{\mathrm{h}_{1}}, \mathrm{t}_{\mathrm{h}_{2}}$ ) só podem ser obtidas tomando-se amostras representativas dos dominios homogêneos (por exemplo, amostras 1 e 2 para the suas RIS dependerão das quantidades relativas de $\mathrm{A}$ e $\mathrm{B}$ na mistura. $A$ consideração de amostras de dominios distintos (por exemplo, $I$ e 4) resulta em isócronas cujas idades não possuem significado temporal e em $R I s$ sem valor interpretativo (por exemplo, $t_{\mathrm{nh}}, R I_{\mathrm{nh}}$ )

Efeitos combinados de assimilação e cristalização fracionada (ACF) Uma das maiores restrições aos modelos de mistura simples é que estes não consideram as variações que ocorrem nos membros finais envolvidos no mecanismo durante seu desenvolvimento, e as modificações simultâneas e/ou posteriores impostas nos sistemas pela cristalização fra cionada, processo sem dúvida fundamental em rochas plutônicas. Modelos mais complexos, como o desenvolvido por Taylor (1980) e De Paolo (1981), tentam sanar pelo menos parte desses problemas ao considerar a atuação conjunta de assimilação e cristalização fracionada (ACF) durante a formação de granitóides a partir de magmas homogêneos. Os tratamentos para modelos deste tipo são bem mais complexos porque devem ser levadas em conta variáveis adicionais, tais como as razões de assimilação e de cristalização (massa de material assimilado/cristalizado por unidade de tempo), a fração de líquido presente em cada estágio do processo e os coeficientes de partição totais dos elementos envolvidos.

Suítes granitóides que evoluíram por ACF resultam em diagramas binários do tipos dos apresentados nas figs. $6 \mathrm{e} 7$, porém, ao contrário do que ocorre com processos de mistura simples, as trajetórias ACF em geral não contém o termo final contaminante. Em diagramas isocrônicos $\mathrm{Rb} / \mathrm{Sr}$, as trajetórias dispõem-se de forma convexa, similar às obtidas por decorrência de cristalização fracionada demorada (De Paolo 1981), portanto trazando conseqüências semelhantes. Correlações lineares, como as apresentadas na Fig. 7, são obtidas apenas quando o fracionamento não afeta os elementos $\mathrm{Rb}$ e $\mathrm{Sr}$ de forma diferenciada, o que é muito improvável.

De modo análogo ao caso anterior comentado, as variações isotópicas do $\mathrm{Sr}$ em função de sua concentração podem ser equacionadas de forma linear, resultando na seguinte equação (Fleck \& Criss 1985):

$$
\begin{aligned}
& Y_{H}-Y_{B}=\left(1 / X_{H}\right)-\left(1 / X_{B}\right) \\
& Y_{A}-Y_{B}=\left(k / X_{A}\right)-\left(l / X_{\mathrm{B}}\right)
\end{aligned}
$$

em que $Y={ }^{87} \mathrm{Sr} /{ }^{86} \mathrm{Sr}, X=\mathrm{Sr} ; k=1+(\mathrm{Mc} / \mathrm{Ma}) .\left(D^{\mathrm{Sr}}-\right.$ 1); Mc é a razão de cristalização; $\mathrm{Ma}$, razão de assimilação; e $\mathrm{D}$, coeficientes de partição total. Os índices $A, B$ e $H$ correspondem ao material assimilado, ao magma original e ao material híbrido, respectivamente. $\mathrm{A}$ análise desta equação mostra que, quando $\mathrm{Ma}>>\mathrm{Mc}$ ou quando $\mathrm{DSr}=1$, resulta o caso já discutido de mistura (Equação 5); por outro lado, se $\mathrm{Ma}<<\mathrm{Mc}$, os resultados são comparáveis aos decorrentes de cristalização fracionada. $\mathrm{Na}$ fig. 8 apresenta-se um diagrama deste tipo - a título de ilustração e de compara- 
ção com os efeitos devidos à mistura simples -, simula-se uma situação realística: considera-se um magma de origem infracrustal $\left(\mathrm{Rb}=50 \mathrm{ppm}, \mathrm{Sr}=400 \mathrm{ppm} \mathrm{e}{ }^{87} \mathrm{Sr} /{ }^{86} \mathrm{Sr}\right.$ $=0,705)$, que assimila materiais supracrustais $(\mathrm{Rb}=150$ $\left.\mathrm{ppm}, \mathrm{Sr}=200 \mathrm{ppm} \mathrm{e}{ }^{87} \mathrm{Sr} /{ }^{86} \mathrm{Sr}=0,740\right)$, quando de sua colocação e cristalização. 0 gráfico resultante (Fig. 8) demonstra mais uma vez que mecanismos de mistura simples são apenas um caso limite de processos mais amplos e com* plexos.

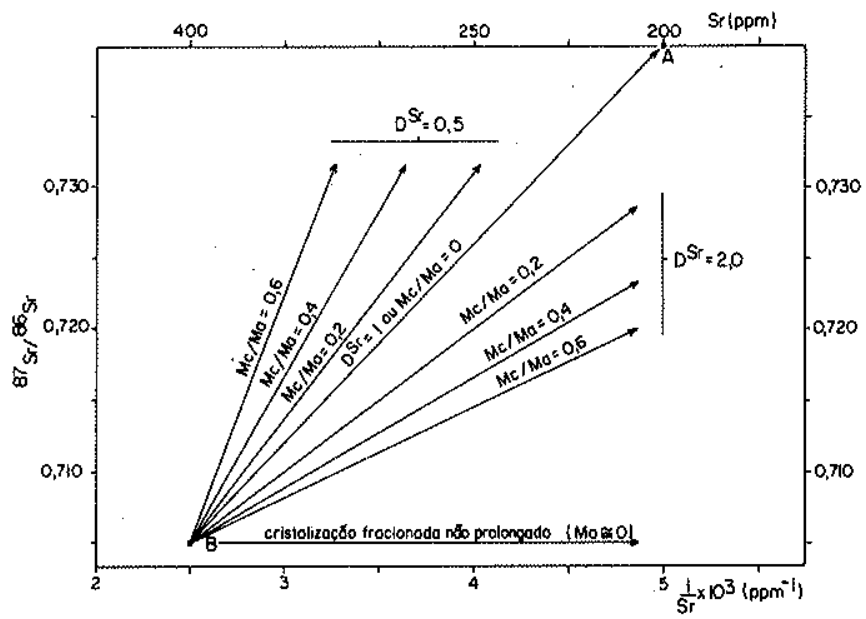

Figura 8 - Diagrama de variaçāo ${ }^{87} \mathrm{Sr} /{ }^{86} \mathrm{Sr}$.vs. $1 / \mathrm{Sr}$ ilustrando possiveis trajetórias decorrentes de processos $A C F$ para diversos valores da razão entre as razões de cristalização (Mc) $e$ de assimilação (Ma) $e$ do coeficiente de partição total do $\mathrm{Sr}(\mathrm{DS})$. [Modelo de Fleck \& Criss (1985)]. $O$ caso simulado é o de um magma homogêneo derivado do manto/crosta inferior, $B\left(S r=400 \mathrm{ppm},{ }^{8} \mathrm{Sr} /{ }^{86} \mathrm{Sr}=\right.$ 0,705), que evolui por cristalização fracionada e, simultaneamente, assimila material supracrustal A $(\mathrm{Sr}=2000$ $\left.\mathrm{ppm},{ }^{87} \mathrm{Sr} /{ }^{86} \mathrm{Sr}=0,740\right)$. Quando $\mathrm{DSr}=1 \mathrm{e} / \mathrm{ou} \mathrm{Mc} / \mathrm{Ma}$ $=0$ a trajetória esperada coincide com a que resulta de fenômenos de mistura simples (ver. Fig. $6 c$ e referências no textol

Considerações adicionais Como se pode concluir dos comentários neste item, os diversos fenômenos potencialmente associados ao desenvolvimento de granitóides co-genéticos afetam, em graus variáveis, a distribuição inicial dos isótopos de $\mathrm{Sr}$, de modo que a premissa pré-estabelecida para conferir significado às idades obtidas pelo cálculo isocrônico (RI fixa e constante) nem sempre é cumprida. Por outro lado, o estudo detalhado dos isótopos de $\mathrm{Sr}$, aliado a informações geológicas, petrográficas e geoquímicas adequadas, fornece informaçōes valiosas para a solução de problemas petrogenéticos, em especial os relacionados com a natureza do material-fonte (ou dos materiais-fontes) dos magmas granitóides e à evolução destes. Finalmente, ainda em relação aos cálculos de idades $\mathrm{Rb} / \mathrm{Sr}$ por meio de isócronas, cumpre salientar que os efeitos sobre os valores numéricos, a exemplo do que ocorre com fenómenos de cristalização fracionada prolongada, são diluídos à medida que as idades aumentam; também são menos pronunciados nos casos em que as isócronas possuem diversos pontos analíticos com valores $\mathrm{Rb} / \mathrm{Sr}$ relativamente elevados, o que as tornam menos dependentes de eventuais variações existentes de RIs.
Os diversos modelos expostos são, evidentemente, meras aproximações de situações naturais. Por exemplo, os modelos de mistura simples não levam em consideração algumas variáveis importantes e a não adaptação de um conjunto de dados às trajetórias previstas em diagramas de mistura não implica diretamente a ausência de processos de hibridismo durante $o$ desenvolvimento dos granitóides considerados (De Paolo 1981).

Em relação à aplicabilidade dos modelos ora comentados a situaçôes reais, fica de certa forma claro, que aqueles em que predominam processos de mistura, com as restrições já colocadas, mostram-se mais adequados em geral para explicar a gênese de suítes vulcânicas; contudo, dados de alguns batólitos recentes parecem sugerir que, pelo menos em alguns casos, as variações observadas são - em uma escala mais ampla - devidas essencialmente a mecanismos de mis. tura simples, como o assinalado (Fleck \& Criss 1985). 0 modelo ACF é, entre os modelos que envolvem hibridismo, o mais abrangente e representa possivelmente melhor as situaçð̃es naturais; porém deve-se lembrar que, também para este modelo, a composição do material contaminante é mantida fixa. Neste sentido, mecanismos mais dinâmicos de assimilação (Myers et al 1983), considerando, adicionalmente, possíveis variações do material assimilado, poderiam traduzir melhor a evolução de algumas suítes granitóides. Entretanto simulações deste tipo são de quantificação extrememente difícil.

\section{ALGUNS EXEMPLOS DE GRANITOIDES BRASI-} LEIROS Como já se salientou no item introdutório, no território brasileiro a sistemática $\mathrm{Rb} / \mathrm{Sr}$ tem sido aplicada essencialmente à determinação radiométrica dos eventos geodinâmicos maiores (Cordani et al. 1973, 1979). E, geral, nestes estudos, as razões iniciais são obtidas diretamente das isócronas traçadas sem considerações especiais para uma melhor caracterização de seus valores, sua precisão e suas variações. Em relação a rochás granitóides, dispõe-se de maior número de dados para as regiôes Sul Sudeste e Nordeste, onde ocorre a maioria das intrusivas brasilianas. Além disso, muitos dados estão disponíveis para a região do Cráton Amazônico, onde ocorrem inúmeras intrusões cratogênicas, em sua maior parte do Proterozóico Médio. Com os dados resultam por excelência de pesquisas de âmbito regional, as amostras escolhidas possuem geralmente razð̋es $\mathrm{Rb} / \mathrm{Sr}$ médias a elevadas e as que são reunidas em diagramas isocrônicos nem sempre são co-genéticas, no sentido da premissa inerente à sistemática $\mathrm{Rb} / \mathrm{Sr}$, de se terem formado na mesma época com a mesma RI.

Estudos mais detalhados sobre variaçôes de RIs em complexos granitóides brasileiros encontram-se em fase de andamento $\mathrm{e}$, atualmente, poucos são os casos para os quais estão disponíveis bom número de dados adequados. Três desses, os complexos de Morungaba e de São Sepé, e o Maciço Jamon, foram selecionados para uma discussão, ao nível geral, das variações isotópicas neies observadas.

As isócronas existentes para esses granitóides incorporam amostras de diferentes afloramentos e de distintas variedades petrográficas, razão pela qual são definidas como isócronas de referência. Em situação ideal de uma sufte co-magmática cristalizada rapidamente e com a RI constante em todos os seus sistemas químicos na época de sua formação, isócronas obtidas de quaisquer conjuntos amostrais devem resultar na idade verdadeira da suíte e apresentar valo- 
res comuns, concordantes dentro dos limites de erro analítico; da mesma forma, a RI de cada amostra considerada deve corresponder à RI obtida na isócrona. Em situações mais realistas, porém, como as comentadas no item ante. rior, podem ser verificadas variações significativas nas RIs; adicionalmente, outros fatores, como os comentados a seguir, podem complicar as interpretações de diagramas isocrônicos.

Observe-se a dispersão dos pontos analíticos que ocorre sempre (ou quase sempre) que se examinam casos reais, como os aqui exemplificados (Figs. 10, 12 e 14, com dados calculados de acordo com o modelo de Williamson 1968). O grau de dispersão dos pontos em relação à isócrona (ou às isócronas) traçada(s) oferece, empiricamente, uma idéia do afastamento das condições reais frente às condições ideais acima expostas. Quatro fatores principais podem ser os responsáveis pelos desvios verificados nos pontos analíticos:

- Erros analiticos. 0 erro experimental representa a possibilidade de desvio em relação ao valor real do parâmetro ${ }^{87} \mathrm{Rb} /{ }^{86} \mathrm{Sr}$ e/ou ${ }^{87} \mathrm{Sr} /{ }^{86} \mathrm{Sr}$ ocasionados pela própria incerteza inerente aos métodos e instrumentos utilizados, e o conhecimento de sua precisão. Nos casos aqui analisados, a razão ${ }^{8} \mathrm{Rb} /{ }^{86} \mathrm{Sr}$ está sujeita a um erro experimental da ordem de $2 \%$ (como indica os diagramas isocrônicos) enquanto a razão ${ }^{87} \mathrm{Sr} /{ }^{86} \mathrm{Sr}$, obtida diretamente em espectrômetro de massa, é conhecida com precisão bem melhor, da ordem de $0,1 \%$ ou menos, e, em geral, não acarreta problemas no posicionamento dos pontos, a não ser nos casos de diagramas isocrônicos com amostras cujas razóes $\mathrm{Rb} / \mathrm{Sr}$ são baixas, como é o caso apresentado na Fig. 14-A.

- Variações reais nas idades de cristalização dos granitói. des de uma suite. É o caso de alguns pontos analíticos que se situam acima ou abaixo da isócrona principal traçada, em geral a reta de melhor ajuste, calculada por técnicas de regressão. Tais pontos afastam-se da reta além das possíveis incertezas experimentais e podem significar que as amostras em questão pertencem a unidades formadas pouco antes ou pouco depois da suite co-genética principal. Estes casos são de difícil detecção visto que as épocas relativas de cristalização são em geral muito próximas no tempo e não acarretam desvios importantes nos diagramas isocrônicos. As situações mais visíveis são, quase sempre, as das variações terminais dos processos de cristalização magmática (por exemplo, microgranitos mais diferenciados, diques aplíticos e pegmatíticos), de razão $\mathrm{Rb} / \mathrm{Sr}$ sempre muito elevada, e cujos pontos se situam, nos diagramas, sempre muito à direita e significativamente abaixo das isócronas principais traçadas.

- Modificaçōes químicas tardias elou posteriores à formação dos granitóides. Trata-se de fatores adquiridos; diversos deles são completamente independentes dos processos formadores dos granitóides. Incluem-se aqui quaisquer modificações que impliquem a alteração das razðes $\mathrm{Rb} / \mathrm{Sr}$ ou ${ }^{87} \mathrm{Sr} /{ }^{86} \mathrm{Sr}$ das amostras estudadas, ocasionando o deslocamento dos pontos analíticos correspondentes nos diagramas isocrônicos. Pode ser o caso de transformações metamórficas (s.s), com formação de fases distintas associadas à mobilização de $\mathrm{Rb}$ e/ou $\mathrm{Sr}$; de transformaçðes tardia pós-magmáticas de homogeneização imperfeita ocasionadas pelo desenvolvimento de sistemas hidrotermais-meteóricos (ver Bonin 1982) ou ainda de alteráções devidas ao intemperismo química

No primeiro caso, a redistribuição dos elementos ou isó- topos se dá, por vezes, ao nível dos minerais, que mantém o sistema fechado ao nível de amostras de "rocha total", fato que possibilita a recuperação de idades e RIs ainda representativas do evento magmático; nas demais situações, os valores obtidos dependem das escalas de homogeneização e das amostras selecionadas, podendo resultar sem significado. No último caso, aliás muito comum nas regiōes tropicais, pode ocorrer remobilização em escalas bem maiores, particularmente do $\mathrm{Sr}$, devido a sua maior mobilidade nas soluções aquosas. Nesta situação, quando as amostras são alteradas de modo a causar perda significativa de $\mathrm{Sr}$, os pontos analíticos respectivos deslocam-se para a direita no diagrama isocrônico (razões $\mathrm{Rb} / \mathrm{Sr}$ maiores) e condicionam idades aparentes mais jovens, sem qualquer expressão geológica.

- Variaçōes originais nas razões ${ }^{87} \mathrm{Sr} /{ }^{86} \mathrm{Sr}$. Este fator é o próprio tema central do trabalho e os principais fenômenos petrogenéticos potencialmente causadores de tais efeitos já foram abordados.

Em uma tentativa de analisar as possíveis consequêencias de variações originais das razões ${ }^{87} \mathrm{Sr} /{ }^{86} \mathrm{Sr}$ nos exemplos de Morungaba, Jamon e São Sepé, fóram elaboradas as Figs. 9 , 11 e 13, em que os valores das RIs relativas a cada amostra foram calculados aplicando-se a Equação (1). Admite-se, como ponto de partida, que as amostras tenham efetivamente a mesma idade - e não teriam sofrido modificações significativas - em relação à edições ou perdas de $\mathrm{Rb}$ e de Sr a partir do momento de formação das rochas.

\section{O Complexo de Morungaba O Complexo de Morungaba} situa-se na região leste do Estado de São Paulo; suas porções oriental e meridional foram estudadas pormenorizadamente por Vlach (1985) e Vlach \& Ulbrich (em prep.). Possui forma alongada segundo as estruturas regionais e é intrusivo em para- e/ortognaisses dos complexos Itapira e Amparo, considerados dos Proterozóico Médio e Inferior. Em sua parte sul, foram reconhecidas duas suítes principais, a saber: suítes Rósea e Cinzenta, cada qual composta por diversas fácies petrográficas. A primeira agrupa, segundo a ordem provável de colocação/resfriamento, fácies a "dois feldspa. tos" (biotita-quartzo-monzonitos e biotita-granitos, em geral com titanita), fácies róseas e brancas (biotita-granitos, em geral com muscovita secundária) e microgranitos e/ou pórifros (granitos com biotita e muscovita secundária). A Suíte Cinzenta, cortada por granitóides róseos e, em parte, a "dois feldspatos", agrupa fácies hololeucocráticas (biotita \pm muscovita granitos, localmente com granada) e fácies leucocráticas (biotitágranitos e granodioritos). Melagranitóides (dioritos a granidioritos e granitos), em parte metamórficos, constituem ocorrências marginais localizadas. A distribuição dos tipos petrográficos, bem como alguns dados modais, é mostrada na figura 9. Em relação à Suíte Rósea, merece destaque o zoneamento observado, com um padrão de certa forma recorrente. Esta suíte apresenta características em parte compatíveis com uma tipologia de granitóides I Caledonianos enquanto as fácies hololeucocráticas da Suíte Cinzenta possuem afinidades com granitóides de tipo $S$. Variedades híbridas, ou de caracterização tipológica mais difícil, também são comuns (Vlach \& Ulbrich, em prep.).

$A$ aplicaçẫo da sistemática $\mathrm{Rb} / \mathrm{Sr}$ em amostras representativas da Suíte Rósea resultou em padrão geocronológico relativamente complicado. Supondo uma RI fixa, da ordem de 0,705, as fácies mais máficas apresentam idades aparentes mais antigas que as fácies mais félsicas; adicionalmente, 

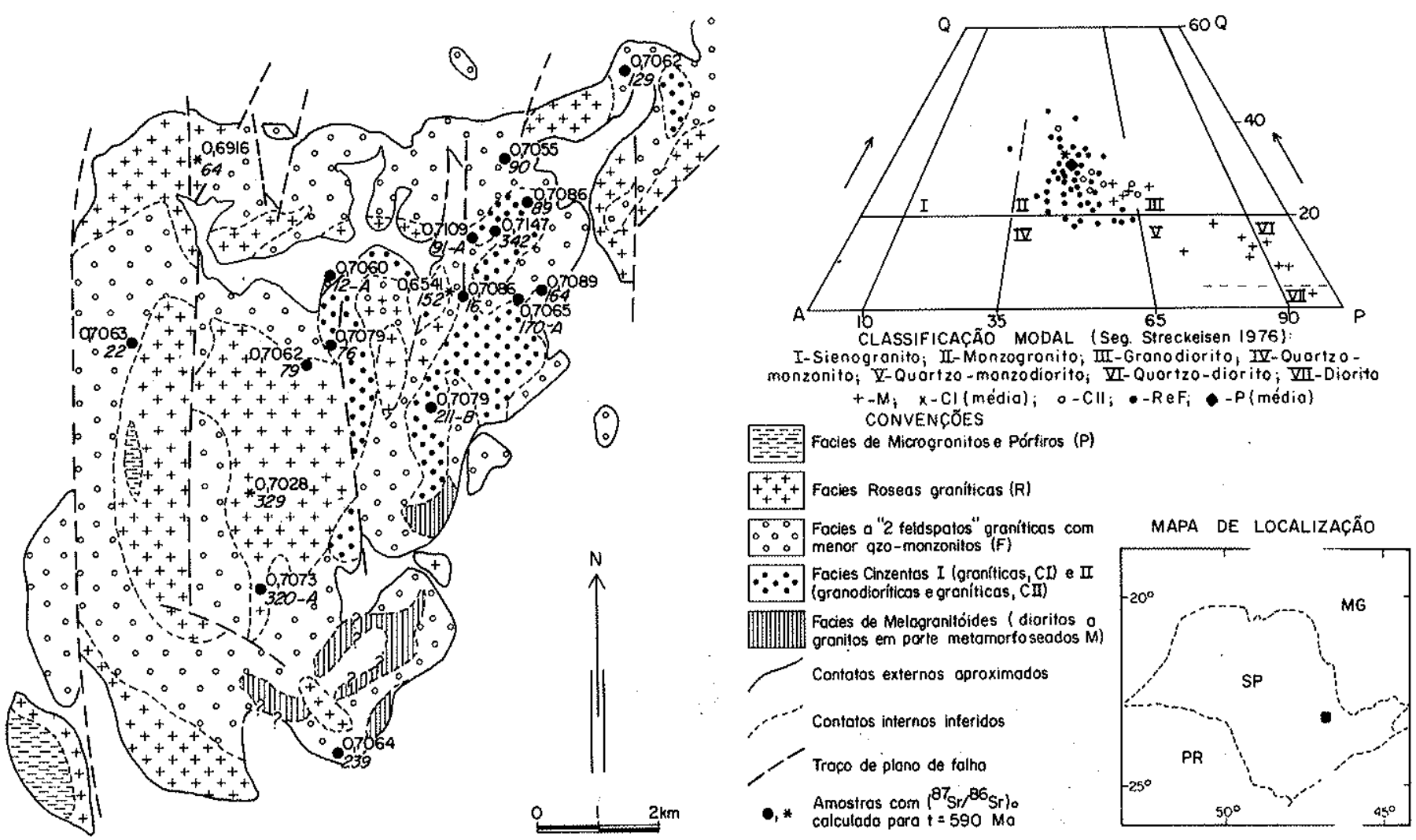

Figura 9 - Mapa geológico da parte Sul do Complexo de Morungaba (simplificado de Vlach 1985), com a localizaçâu de amostras analisadas e respectivos valores de RI calculados para a idade de formação dos granitóides (ver texto)

as fácies félsicas mais diferenciadas resultam em idades aparentes anomalamente jovens, havendo um intervalo entre as manifestações limites em torno de $200 \mathrm{Ma}$ (Vlach \& Kawashita 1984, Vlach 1985). Um diagrama isocrônico de referềncia, reunindo todas as fácies (Fig. 10), indica que a grande maioria dos pontos analíticos, com exceção dos tipos róseos mais diferenciados, agrupa-se nas proximidades de retas de ajuste de $590 \mathrm{Ma}$. Se forem consideradas isoladamente as fácies hololeucocráticas da Suíte Cinzenta, a idade isocrônica resultante indica o mesmo valor de $590 \mathrm{Ma}$.

Calculando-se os dados disponiveis por regressão, de acordo com o método preconizado por Williamson (1968), obtém-se a idade de $590 \pm 10 \mathrm{Ma}$ e a $\mathrm{RI}=0,70636 \pm$ 0,0025 para a Suíte Rósea e a idade de $590 \pm 20$ Ma com $\mathrm{RI}=0,70873 \pm 0,00264$ para a Suf́te Cinzenta (fácies hololeucocráticas). Na figura 10 , observa-se que são poucos os pontos analíticos que se situam claramente fora dos alinhamentos traçados. São exemplos o granitóide cinzento hololeucocrático de número 342 , cujo ponto está acima da isócrona, e os granitóides de número 64,152 e 329 , situados abaixo das isócronas. Estes últimos resultam em valores absurdos para as RIs (inferiores a 0,703), tal como aparecem na figura 9.

A figura 9 foi elaborada calculando-se as RIs mediante 0 emprego do valor de $590 \mathrm{Ma}$ de idade para todas as amostras, de acordo com a equação (1). Com exceção das amostras enumeradas acima, de valores de RI não realísticos, as demais se apresentam compatíveis com o modelo preconizado e devem realmente refletir variaçбes nas razões iniciais dos sistemas, na época da cristalização dos magmas granitóides. Os valores estão compreendidos entre 0,705 e 0,715,

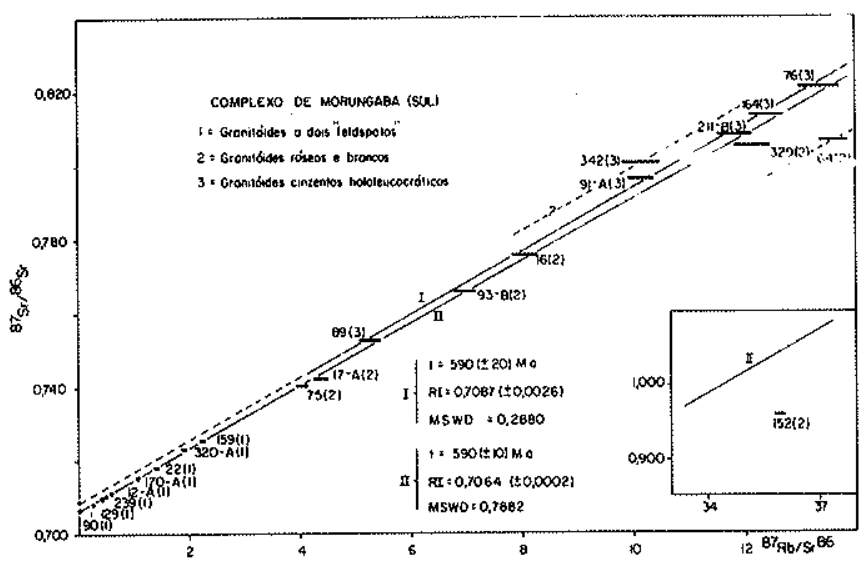

Figura 10 - Diagrama isocrônico de referência para as suites Rósea e Cinzenta do Complexo de Morungaba (valores recalculados de Vlach 1985). As amostras 17-A, 93-B e 159 não constam na Figura 9 por estarem localizadas fora da área apresentada

os mais elevados correspondendo sempre às variedades hololeucocráticàs da Suíte Cinzenta.

Os dados da RI da Suíte Cinzenta estão sujeitos a erros experimentais elevados, que se explica pelo fato de tais granitóides possuírem razões $\mathrm{Rb} / \mathrm{Sr}$ relativamente elevadas, não estando disponíveis amostras com razões $\mathrm{Rb} / \mathrm{Sr}$ mais baixas, as quais melhorassem a qualidade da isócrona. Dentro do erro admitido, as RIs desses granitóides são praticamente constantes, no intervalo $0,709 \pm 0,002$; apenas a 
amostra de número 342 apresenta-se relativamente enriquecida em $\mathrm{Sr}$ radiogênico, o que deve ser decorrente da presença, nesta, de glomérulos máficos (restitos de material mais antigo?) com minerais peraluminosos (Vlach \& Ul brich, em prep.).

A respeito da Suíte Rósea, as amostras analisadas resultam em valores próximos a 0,707 e os dados analíticos parecem sugerir um certo aumento de $\mathrm{Sr}$ radiogênico em direção às variedades mais félsicas, fato que culmina com idades isocrônicas fictícias e mais antigas ( $\sim 650 \mathrm{Ma}$, Vlach 1985) para as rochas mais máficas quando consideradas isoladamente, de acordo com mecanismos como os apresentados no item anterior. São necessários, porém, dados adicionais de tipo geoquímico e, principalmente, de tipo isotópico com melhor resolução para confirmar tal interpretação e, na medida do possível, discriminar entre os processos discutidos o mais atuante. Em relação aos granitóides róseos mais diferenciados (amostras 64, 152 e 329) com dados anômalos, existiria a possibilidade de que esses representassem eventos mais jovens ( $440-500 \mathrm{Ma}$ ); entretanto tal suposição conflita com observações geológicas e dados radiométricos K/Ar (Vlach 1985), devendo ser concluído, portanto, que tais amostras representam sistemas empobrecidos em $\mathrm{Sr}$, que perderam quantidades significativas deste elemento por efeitos hidrotermais-meteóricos posteriores à cristalização dos magmas, ou, com menor probabilidade, que tais rochas representam líquidos "congelados", de razões $\mathrm{Rb} / \mathrm{Sr}$ mais elevadas, do modo visualizado por McCarthy e Cawthorn (1978).
O Maciço Jamon O Maciço Jamon localiza-se na Região Amazônica (PA) e foi estudado com detalhe por Dall'Agnol (1980). Sua sistemática Rb/Sr é discutida por Dall'Agnol et al. (1984). Trata-se de uma intrusão anorogênica, pós-transamazônica, colocada em sua maior parte em excaixantes granodioríticas tidas como pertencentes ao "embasamento", na região o Complexo Xingú, tal como define o Projeto Radam. No maciço, são reconhecidas quatro variedades petrográficas principais, dispostas segundo um padrão normal de zoneamento, com variações graduais entre si. São elas: biotita-granitos equigranulares (GE) e inequigranulares (GH), ambos com hornblenda e titanita; garnitos alsquíticos (GAL) com biotita e microgranitos porfiríticos (MG), ambos com ou sem titanita. A distribuição dessas variedades e dados modais disponíveis são reproduzidos na figura 11 , adaptada de Dall'Agnol (1980). Este autor conclui que as quatro fácies petrográficas estão relacionadas entre si por cristalização fracionada moderada, a partir do mesmo magma parental, que produzem, então, a evolução $\mathrm{GE} \rightarrow \mathrm{GH} \rightarrow$ MG e, paralelamente, GE $\rightarrow$ GAL. Tal magma seria resultante de fusão parcial de rochas ígneas crustais e os granitóides apresentam afinidades com os granitóides do tipo I Caledoniano.

Dall'Agnol et al. (1984) apresentam 10 análises $\mathrm{Rb} / \mathrm{Sr}$ para as diversas variedades descritas que, calculadas segundo o diagrama isocrônicos da figura 12 , definem uma isócrona de $1.585 \pm 25 \mathrm{Ma}$, com RI $=0,7126 \pm 0,0016$. As amostras dispõem-se em um intervalo muito favorável no diagrama isocrônico e a reta de melhor ajuste traçada é de boa quali-
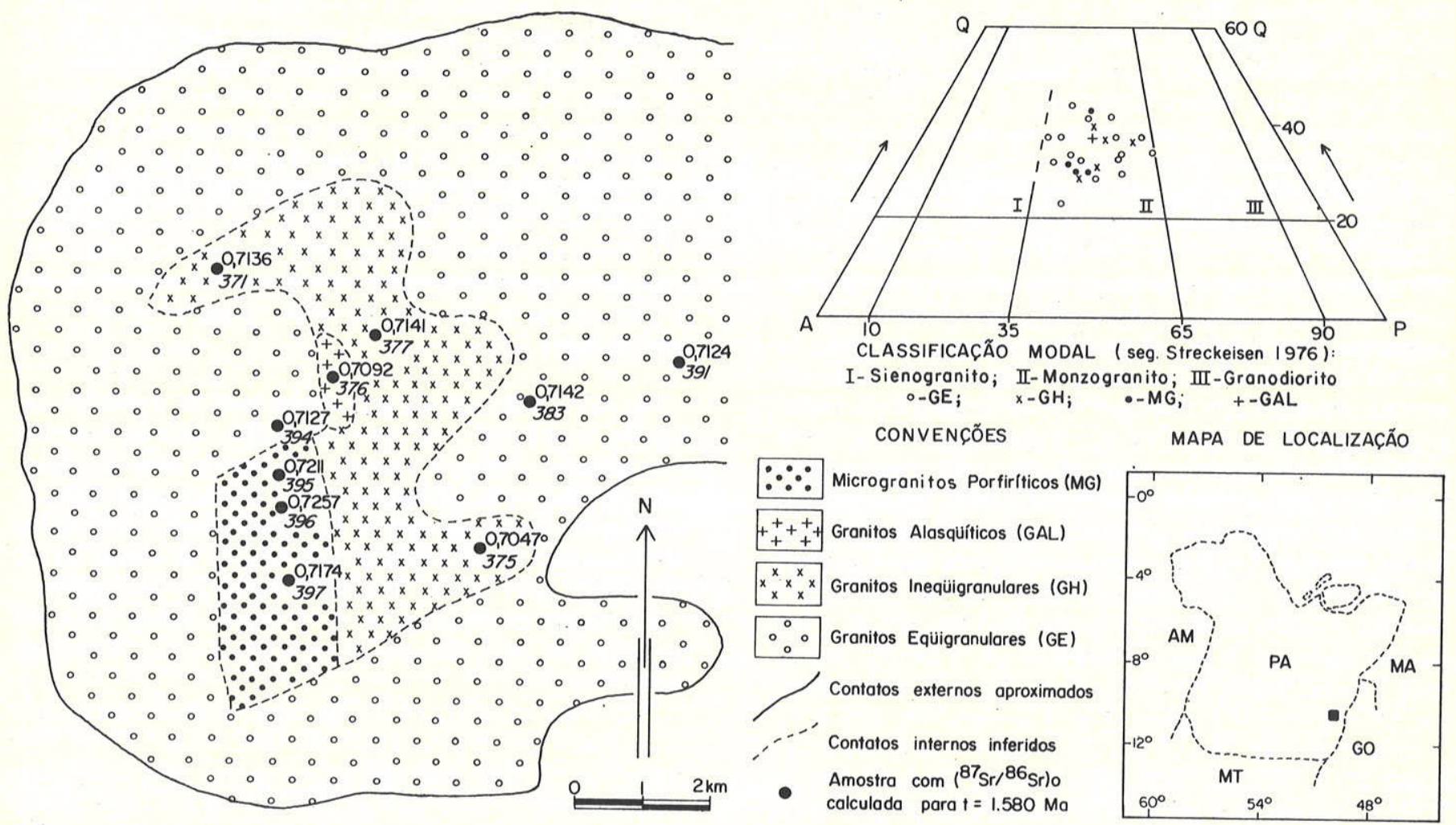

Figura 11 - Mapa geológico do Maciço Jamon (segundo Dall'Agnol 1980), com localização de amostras analisadas por Dall'Agnol et al. (1984) e as RIs calculadas para a idade de formação dos granitóides (ver texto) 
dade analítica; a maioria dos pontos analíticos é, de fato, co-linear, ou quase, dentro dos erros experimentais individuais.

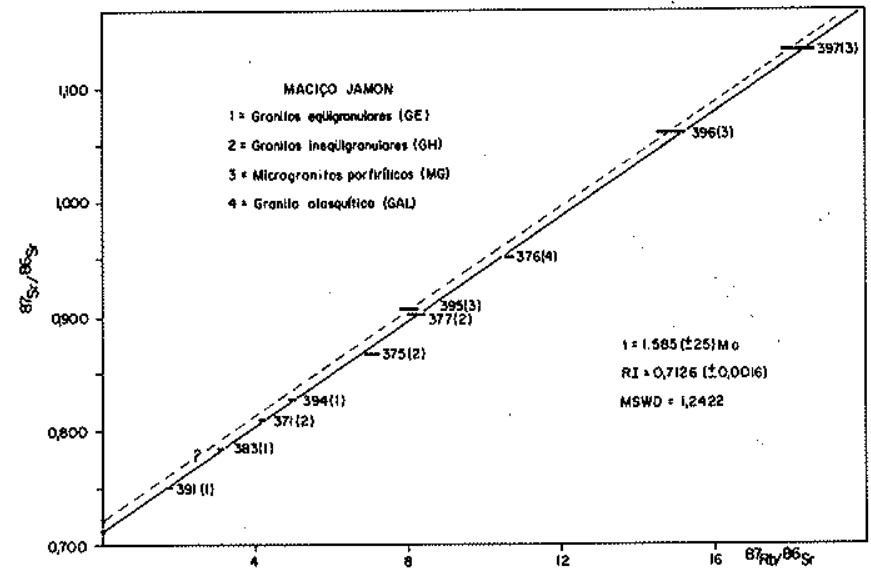

Figura 12 - Diagrama isocrônico de referência para gar. nitóides do Maciço Jamon (valores recalculados de Dall'Agnol et al. 1984)

Supondo que as rochas sejam absolutamente sincrônicas e que a dispersão observada seja devida apenas a variações na razão inicial, calcularam-se os valores desta para cada amostra, de acordo com o procedimento adotado no caso anterior. As RIs acham-se representadas na figura 11.

A observação dos resultados mostra que existem variações significativas, bem superiores aos erros estimados (admitidos, por simplicidade, como semelhantes ao erro da RI isocrônica), verificando-se que as amostras de números $\mathbf{3 7 5}$ e 376 apresentam valores baixos, inferiores a 0,709. Nestes casos, é possível que tenha havido alguma perda de $\mathrm{Sr}$ decorrente de fenômenos posteriores à cristalização magmática, mas não pode ser excluŕda, com os dados disponíveis, a hipótese de estas rochas serem pouco mais jovens que as demais. Por outro lado, as amostras de números $395,396 \mathrm{e}$ 397 apresentam valores relativamente muito elevados; é interessante observar que todas essas correspondem aos microgranitos porfíríticos, os quais apresentam, em geral, as maiores razões $\mathrm{Rb} / \mathrm{Sr}$. Tais variações sugerem que os microgranitos possuem contribuições mais relevantes de $\mathrm{Sr}$ radiogênico, quando comparados aos demais granitóides; como essas rochas não possuem manifestações tardi- a pós-magmáticas muito pronunciadas (Dall'Agnol 1980), é possível que as variações assinaladas representem condições genético-evolutivas próprias, distintas e relacionadas com os respectivos materiais-fontes. Adicionalmente, não pode ser descartada também a hipótese de essas rochas corresponderem a um sistema químico isolado, independente, formado pouco após a consolidação das demais fases. De fato, uma isócrona, tentativamente traçada (Fig. 12), reunindo apenas os pontos analíticos 395,396 e 397 sugere uma idade semelhante $(\sim 1.580 \mathrm{Ma})$ com uma RI bem mais elevada ( $~$ 0,7213 ), porém, face ao número reduzido de pontos analíticos, a sua distribuição e a seu distanciamento da origem do diagrama isocrônico, os erros envolvidos nesses valores são muito elevados. De qualquer forma, parece razoável supor, com os dados ora disponíveis, que os microgranitos porfiríticos possuem quantidades maiores de $\mathrm{Sr}$ radiogênico, adquiridas quer por fusão de fonte distinta, mais rica em ${ }^{87} \mathrm{Sr}$, quer por interação com sistemas mais evoluídos isotopicamente.

- Complexo de São Sepé O Complexo de São Sepé (RS) foi objeto de estudos pormenorizados realizados por Sartori (1978). Possui forma alongada e suas fácies marginais são intrusivas em metassedimentos do Grupo Porongos e, em parte, em rochas sedimentares e vulcânicas das formações Maricá e Hilário, as quais, em geral, mostram evidências variáveis de metamorfismo de contato; a maior parte de seus contatos, contudo, está encoberta por sedimentos permocarboníferos da Bacia do Paraná. O complexo é constituído por quatro variedades granitóides principais que incluem biotita-granitos porfiríticos, em geral com hornblenda e titanita; biotita-granitos equigranulares com ou sem titanita; e microgranitos porfiríticos com biotita e alguma muscovita secundária. A disposição dessas variedades e os dados modais disponíveis são reproduzidos na figura 13 . É interessante observar que este complexo apresenta zoneamento inverso e caráter petrográfico bimodal; suas características gerais são, em parte, similares as dos granitóides de tipo I Caledoniano.

Segundo Sartori (1978), os granitóides centrais, mais máficos, seriam representativos do magmatismo brasiliano sin-tectônico e os granitóides periféricos da fase pós-tectônica. Os microgranitos mais diferenciados (não representados na figura 13) estariam associados a uma fase tardia - contemporânea ao resfriamento e ao soerguimento regionais do cinturão orogênico. As razões iniciais de cada grupo indicariam materiais-fontes progressivamente mais ricos em $\mathrm{Sr}$ radiogênico. Os dados do autor, recalculados de modo análogo aos casos anteriores, resultam em idades de $670 \pm 75 \mathrm{Ma}$, $525 \pm 10 \mathrm{MA}, 440 \pm 10 \mathrm{Ma}$, com RIs de 0,7063 $\pm 0,0022$, $0,7081 \pm 0,0024$ e $0,7495 \pm 0,0070$ para os granitóides centrais, periféricos e microgranitos, respectivamente (Fig. 14). A distribuição das RIs por amostra, supondo como nos casos anteriores (Morungaba e Jamon) que as dispersões são devidas apenas às variações na razão inicial, pode ser observada na figura 13 .

Os dados relativos aos granitóides centrais e periféricos, quando considerados os erros estimados, são relativamente homogêneos; porém o mesmo não ocorre com as rochas mais félsicas - os microgranitos -, valendo para estas as observações efetuadas para as variedades mais diferenciadas do Complexo de Morungaba. Em relação às rochas de razões $\mathrm{Rb} / \mathrm{Sr}$ mais baixas, lozalizadas no núcleo do complexo - a exemplo de Morungaba --, verifica-se que os erros decorrentes da determinação de suas idades isocrônicas são muito elevados.

Também no Compelxo de São Sepé, os resultados isocrônicos $\mathrm{Rb} / \mathrm{Sr}$ são compatíveis com uma longa história evolutiva ( $\sim 150-200 \mathrm{Ma}$ ), que é, em parte, sustentada pelo nítido caráter bimodal dos granitóides das presentes (granitóides centrais mais máficos por um lado, granitóides periféricos e microgranitos mais félsicos pelo outro), fato aparentemente sugestivo de eventos distintos, tanto do ponto de vista genético, como temporal. 


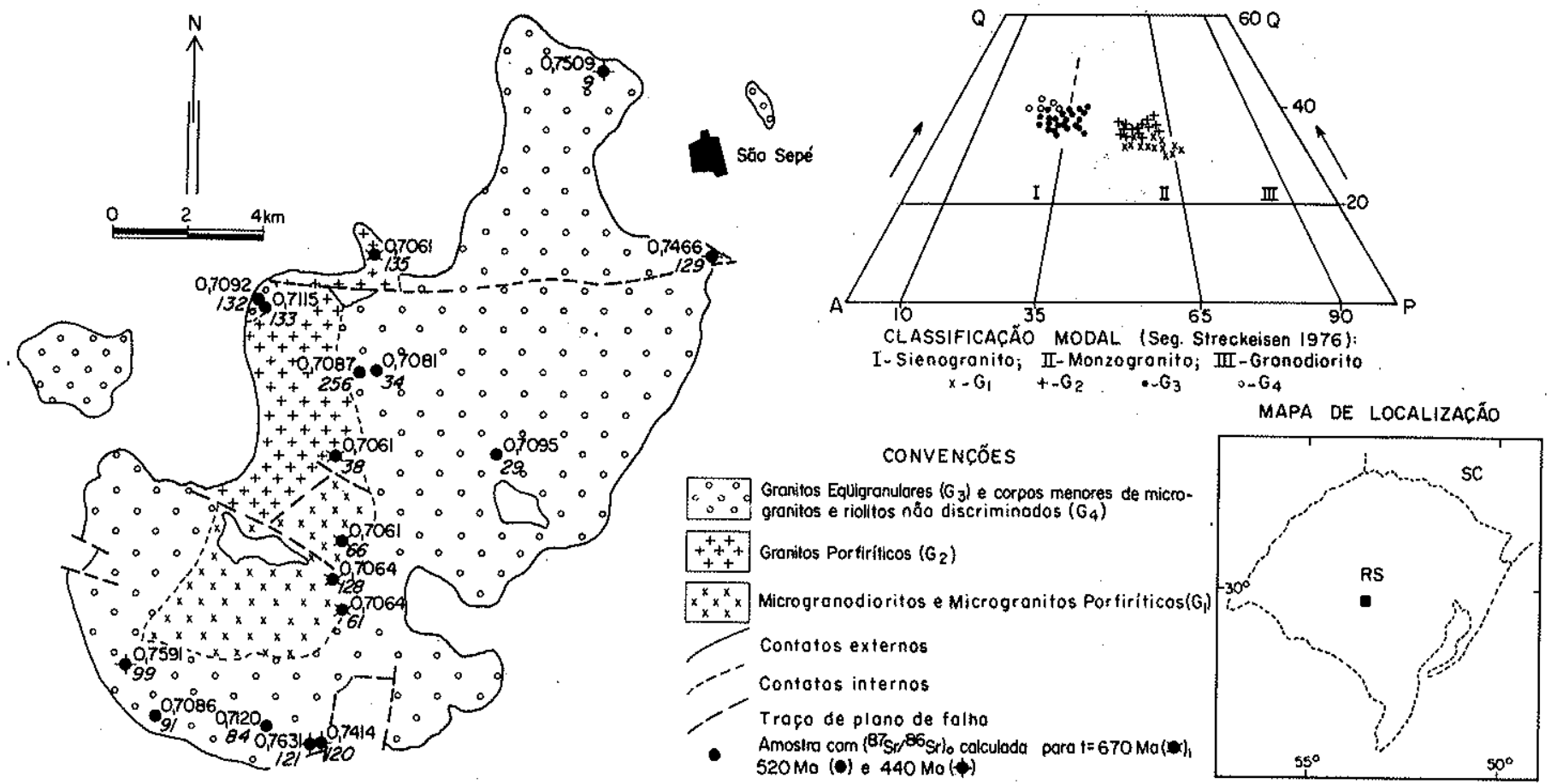

Figura 13 - Mapa geológico do Complexo de São Sepé (simplificado de Sartori 1978), com a localização de amostras analisadas e respectivas RIs calculadas para a idade de formação dos granitóides (ver texto)
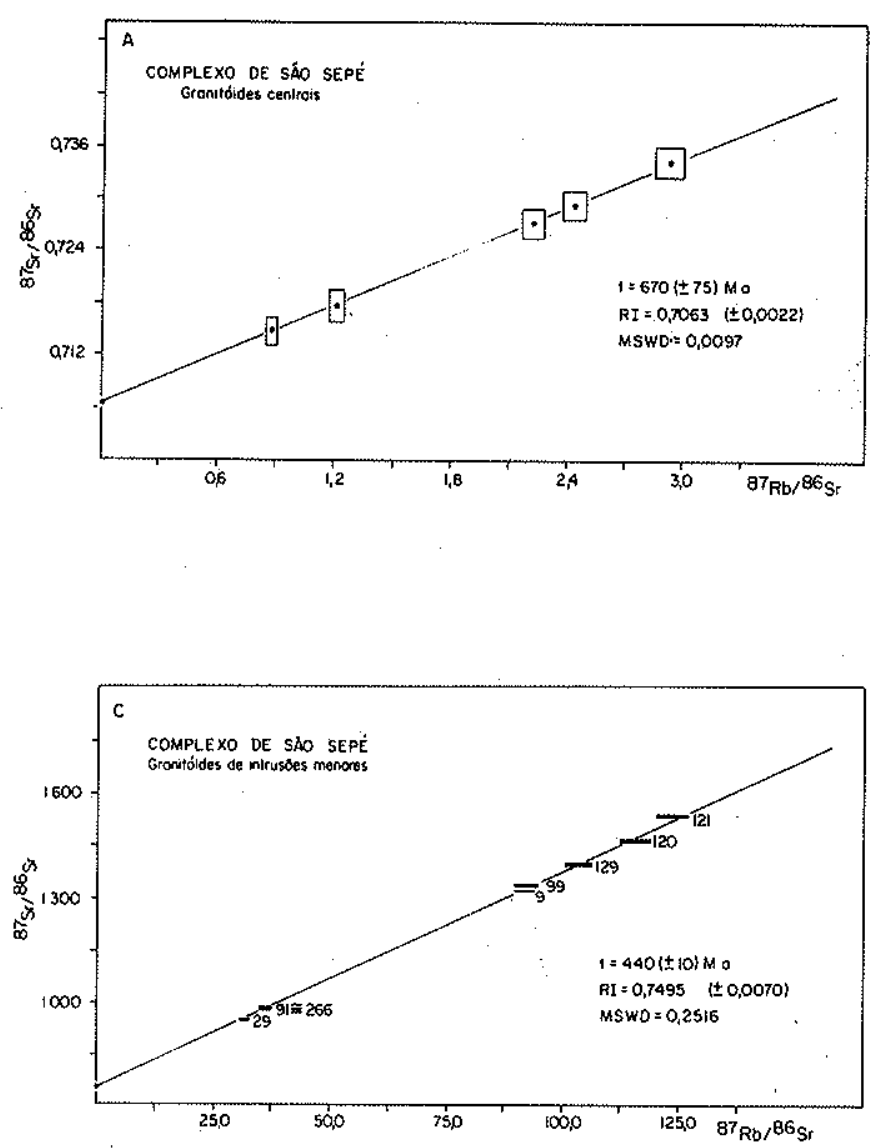

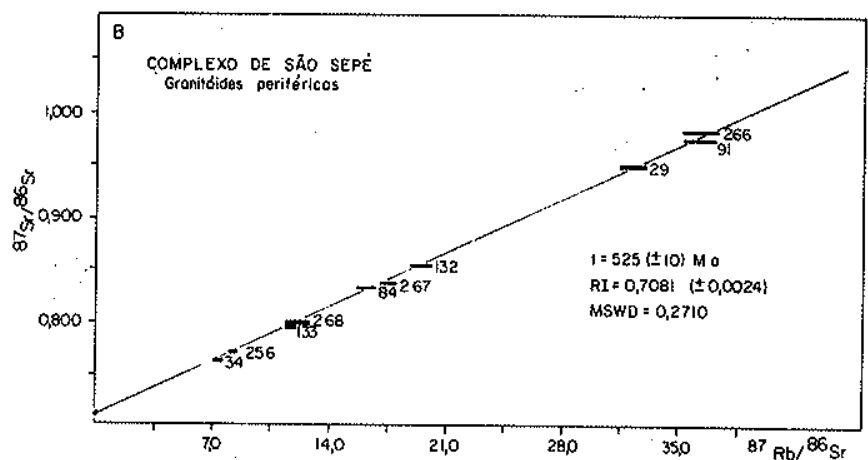

Figura 14 - Diagramas isocrônicos de referência para granitóides do Complexo dee São Sepé (valores recalculados de Sartori 1978): granitóides centrais (A); granitóides marginais (B); e intrusões menores (C). A amostra 266, representativa de um pequeno corpo a $S E$ de Säo Sepé, não está representada na Fig. 13

CONSIDERAÇÕES FINAIS A revisão de alguns dos conceitos da sistemática $\mathrm{Rb} / \mathrm{Sr}$ efetuada neste trabalho demosntra as potencialidades do método como indicador genético e evolutivo para suítes granitóides e, ao mesmo tempo, ressalta as principais limitações da metodologia, que sugerem alguns dos cuidados que devem ser lembrados quando das interpretações de dados isotópicos $\mathrm{Rb} / \mathrm{Sr}$ disponíveis para essas rochas. Foram comentados diversos modelos genético-evolutivos potencialmente envolvidos na forma- 
ção de granitóides e simuladas algumas de suas possíveis conseqüências sobre a distribuição dos isótopos de Sr. A análise de alguns exemplos sugere, pelo menos em parte, sua viabilidade interpretativa no sentido de explicar algumas das variaçõees isotópicas observadas como resultantes de variações iniciais no parâmetro ${ }^{87} \mathrm{Sr} /{ }^{86} \mathrm{Sr}$. Por outro lado, verifica-se também que, para interpretações mais definitivas, são necessários dados isotópicos de maior resolução associados a outros controles geoquímicos; obviamente, a interpretação final da gênese e da evolução de uma suíte qualquer deve resultar de um conjunto de evidências geológicas, petrográficas, geoquímicas e isotópicas. Os exemplos comentados mostram, adicionalmente, a necessidade de verificar a possível existência de fenômenos hidrotermais-meteóricos, os quais podem causar a abertura dos sistemas químicos e conseqüente perda de $\mathrm{Sr}$, fator particularmente importante nos diferenciados mais tardios (por exemplo, granitos "aplíticos"), devido a seus teores baixos em Sr. Atualmente, tais fenômenos podem ser detectados de forma adequada com a utilização de isótopos de $\mathrm{O}$ e de $\mathrm{H}$.

Torna-se clara a importância de amostragem adequada para a obtenção de dados mais acurados e de melhor qualidade, o que está diretamente ligado ao conhecimento das características geológicas e petrográficas das rochas estudadas. A amostragem ideal - em que se tomam diversas amostras do mesmo afloramento, homogêneo dos pontos de vista estrutural e petrográfico, ou mesmo não tão ideal, quando se tomam amostras da mesma fácies petrográfica de afloramentos distintos, supostamente interligados - com freqüência não resulta em dispersão adequada dos valores $\mathrm{Rb} / \mathrm{Sr}$ para a construção de isócronas de boa qualidade. Por outro lado, se existem variações composicionais de monta, existe também a possibilidade de que tais variações estejam, pelo menos em parte, condicionadas por processos como os discutidos, atuando sobre domínios químicos isotopicamente heterogêneos. Amostras do mesmo afloramento, onde ocorrem tipos petrográficos distintos, com relações de contato bruscas e/ou intrusivas, podem representar sistemas químicos próprios com razões ${ }^{87} \mathrm{Sr} /{ }^{86} \mathrm{Sr}$ próprias, características e diferentes dos sistemas adjacentes.

$\mathrm{O}$ caso mais comum em amostragem de granitóides para estudos geocronológicos é aquele em que as amostras provêm de afloramentos distanciados em graus variáveis e re- presentam variedades petrográficas distintas. Nessas ocasiões, dados geológicos e petrográficos são extremamente importantes para a sepação entre os granitóides presentes e para tentar definir as unidades intrusivas (Ulbrich 1984) existentes, bem como sua cronologia relativa. Isócronas de sistemas realmente co-genéticos, no sentido de satisfazer aos requisitos impostos pela Equação (1), só podem ser obtidas a partir de amostras tomadas:

- de domínios homogêneos da mesma unidade intrusiva ou - de domínios de diferentes unidades intrusivas, desde que estas estejam relacionadas por fracionamento a partir do mesmo magma parental homogêneo e que os intervalos de tempo decorridos entre as consolidações das diferentes unidades não sejam muito prolongados.

Naturalmente, as variações isotópicas de se esperar para uma mesma suíte são de pequena monta e para efeitos de cálculos de idades $\mathrm{Rb} / \mathrm{Sr}$ e obtenção de indicações genéricas de suas RIs, isócronas de referência de granitóides co-genéticos (1.s), considerando amostras com boa dispersão das razões $\mathrm{Rb} / \mathrm{Sr}$, resultam em valores quase sempre significativos. Deve-se cuidar, contudo, de valores obtidos com amostras de razões $\mathrm{Rb} / \mathrm{Sr}$ muito elevadas.

Para efeito de estudos mais detalhados, considerando possíveis variações isotópicas dentro de uma suíte, é recomendável ter-se um controle das idades dos granitóides mediante métodos alternativos (por exemplo, $\mathrm{U} / \mathrm{Pb}$ em zircões), particularmente porque os domínios homogêneos apresentam, em geral, pouca dispersão $\mathrm{Rb} / \mathrm{Sr}$, o que acarreta erros elevados nas determinações radiométricas, em especial nos casos em que temos razões $\mathrm{Rb} / \mathrm{Sr}$ baixas.

Agradecimentos Os autores agradecem ao CPGeo-USP pelas facilidades na obtenção dos dados geocronológicos; ao Dr. Alcides N. Sial, coordenador do Workshop sobre Granitogênese e Mineralizações Asssociadas, no qual este trabalho foi apresentado, e posteriormente redigido; à Sra. Maria J. Silva pela datilografia; e ao Sr. Paulo C.O. dos Santos pelos desenhos. SRFV agradece auxílios FAPESP (Proc. 81/1506-2 e 83/1269-6) e CNPq (Proc. 40.1382/83 e 40.969/83), beneficiário $\mathrm{H}$. Ulbrich.

\section{REFERÊNCIAS BIBLIOGRAFICAS}

ALLĖGRE, C.J. \& MINSTER, J.F. - 1978 - Quantitative models of trace element behavior in magmatic processes. Earth Planet. Sci. Lett., 38:1-25.

ALLĖGRE, C.J.; HART, S.R.; MINSTER, J.G. - 1983 - Chemical structure and evolution of the mantle and continents determined by inversion of $\mathrm{Nd}$ and $\mathrm{Sr}$ isotopic data. II: Numerical experiments and discussion. Earth Planet. Sci. Lett., $66: 191-213$.

BONIN, B. - 1982 - Les granites de complexes annulaires. Bureau de rechercher géologiques et minières. Manuels of Méthods, 4 . Orleans, BRGM. $176 \mathrm{p}$.

BROWN, G.C. - 1977 - Mantle origin of cordilleran granites. Nature, 265:21-24,

COMPSTON, E. \& CHAPPELL, B.W. - $1979-\mathrm{Sr}$ isotope evolution of granitoid source rocks. In: McELHINNY, M.W. ed. The earth: Its origin, structure and evolution. London, Academic Press. p. 377-426.
CORDANI, U.G. - 1980 - Fundamentos de interpretação geocronológica. In: CONGR. BRAS. GEOL., 31, Camboriú, 1980. Cursos... Camboria, SBG, Bol. 6, p. 5-22.

CORDANI, U.G.; DELHAL, J.; LEDENT, D. - 1973 - Orogénèses superposées dans le Precambrian du Bresil Sud-Orientale (États de Rio de Janeiro et de Minas Gerais). Rev. Bras. Geoc., 3(1):1-22.

CORDANI, U.G.; TASSINARI, C.G.C.; TEIXEIRA, W.; BASEI, M.A.S.; KAWASHITA, K. - 1979 - Evolução tectônica da Amazônia com base nos dados geocronológicos. In: CONGR. GEOL. CHILE, 2, Aricas, 1979. Actas... Aricas, p. J137-J148.

COX, K.G.; BELL, J.D.; PANKHURST, R.J. - 1979 - The interpretation of igneous rocks. London, George Allen \& Unwin. $450 \mathrm{p}$.

DALL'AGNOL, R. - 1980 - Etudes sur des granites du type "Rondonian" en Amazonie Orientale et leurs transformations tardi-magmatiques. (Thèse Troisiène Cycle, inédita, Toulouse, 
Univers. Paul Sabatier). 348 p.

DALL'AGNOL, R.; SCHUCKMANN, W.K.; BASEI, M.A.S. SCHELER, T. - 1984 - Novos dados geocronológicos e estudo de elementos-traços de maciços graníticos anorogênicos da Amazônia Oriental, Estado do Pará (Brasil). In: SIMP. AMAZÔNICO, 2, Manaus, 1984. Anais... Manaus, DNPM, p. 59-74.

DE PAOLO, D.J. - 1981 - Trace elements and isotopic effects of combined wallrock assimilation and fractional crystallization. Earth Planet. Sci. Lett., 53:189-202.

DIDIER, J.; DUTHOU, J.L.; LAMEYRE, J. - 1982 - Mantle and crustal granites: genetic classification of orogenic granites and the nature of their enclaves. J. Volcan. Geoth. Res., 14:125132.

FAURE, G. - 1977 - - Principles of isotopic geology. New York, John Wiley, $464 \mathrm{p}$.

FAURE, G. \& POWELL, J.L. - 1972 - Strontium isotope geology. Berlin, Springer-Verlag. $188 \mathrm{p}$.

FLECK, R.J. \& CRISS, R.E. - 1985 - Strontium and oxygen isotopic cariations in mesozoic and tertiary plutons of Central Idaho. Contr. Mineral. Petrol., 90:291-308.

HARMON, R.S.; HAELLIDAY, A.N.; CLAYBURN, J.A.P.; STEPHENS, W.E. - 1984 - Chemical and isotopic systematics of the Caledonian instrusions of Scotland and Northern England: a guide to magma source region and magma-crust interaction. Phil. Trans. R. Soc. London, 310(A):693-707.

HURLEY, P.M.; BATEMAN, P.C.; FAIRBAIRN, H.W.; PINSON JR., W.H. - 1965 - Investigation of initial ${ }^{87} \mathrm{Sr} / 86 \mathrm{ratios}$ in the Sierra Nevada Plutonic Province. Bull. Geol. Soc. Amer., $76: 165-174$

LAMEYRE, J. \& BOWDEN, P. - 1982 - Plutonic rock type series: discrimination of various granitoid series and related rocks. J. Volcan. Geoth. Res., 14:169-189.

LANGMUIR, D.H.; VOCKE Jr, R.D.; HANDSON, G.N.; HART, S.R. - 1978 - A general mixing equation with applications to icelandic basalts. Earth Planet. Sci. Lett., 37:380-392.

McCARTHY T.S. \& CAWTHORN, R.G. - 1978 - Changes in initial ${ }^{87} \mathrm{Sr} /{ }^{86} \mathrm{Sr}$ ratio during protracted fractionation igneous complexes. J. Petrol., 21:245-264.

McCULLOCH, M.T. \& HENSEL, H. - 1984 - Sm-Nd isotopic evidence for a major early to mid-proterozoic episode of crustal growth in the australian continent. In: INTERN. GEOL. CONGR., 27, Moscou, 1984. Abstracts... Moscou, v. 2, p. 351-352.

MOORBATH, S. \& TAYLOR, P.N. - 1981 - Isotopic evidence for continental growth in the precambrian. In: KRÖNER, A. ed. Precambrian plate tectonics. Amsterdan, Elsevier, p. 491-525.

MYERS, J.D.; SINHA, A.K.; MARSH, B.D. - 1984 - Assimilation of crustal material by basaltic magma. Strontium isotopic and trace element data from the Edgecumbe Volcanic Field, SE Alaska. J. Petrol., 25(1):1-26.

NICOLAYSEN, L.O. - 1961 - Graphic interpretation of discordant age measurements of metamorphic rocks. Ann. N.Y. Acad. Sci., 91(2):198-206.

PAGE, R.W.; McCULLOCH, M.T.; BLACK, L.P. - 1984 - Isotopic record of major precambrian events in Australia. In: INTERN. GEOL. CONGR., 27, Moscou, 1984. Proceedings... Moscou, v. 5, p. 25-72.istema Hermétic

PANKHURST, R.J. - 1979 - Isotope and trace element evidence for the origin and evolution of caledonian granites in the Scottish High lands. In: ATHERTON, M.P. \& TARNEY, J. ed. Origin of granite batholiths: Geochemical evidence. Nantwich, Shiva, p. 18-33.
PAPANASTASSIOU, D.A. \& WASSERBURG, G.J. - 1969 - Initial strontium isotopic abundances and the resolution of small time differences in the formation of planetary objects. Earth Planet. Sci. Lett., 5:361-376.

PEARCE, J.A.; HARRIS, N.B.W.; TINDLE, A.G. - 1984 - Trace element discrimination diagrams for the tectonic interpretation of granitic rocks. J. Petrol., 25(4):956-983.

PITCHER, W.S. - 1983 - Granite type and tectonic environment. In: HSÜ, K.J. ed. Mountain building processes. London, Academic Press. p. 19-40.

READ, H.H. - 1957 - The granite controversy. Geological address illustrating the evolution of a disputant. Herstford, Thomas Murby. 430 p.

RODDICK, J.C. \& COMPSTON, W. - 1977 - Strontium isotopic equilibration: a solution to a paradox. Earth Planet. Sci. Lett., $34: 238-246$.

SARTORI, P.L.P. - 1978 - Petrologia do Complexo granítico de São Sepé, RS: modelo evolucional de granitos do Sul do Brasil. São Paulo. (Tese de Doutoramento, IG-USP). 196 p.

STEIGER, R.H. \& JAGER, E. - 1977 - Subcomission on geochronology; convenction on the use of decay constants in geochronology and cosmochronology. Earth Planet. Sci. Lett., 36: 359-362.

STRECKEISEN, A. - 1976 - To each rock its proper name. Earth Sci. Rev., 12:1-33.

TAYLOR, S.R. - 1964 - Abundance of chemical elements in the continental crust: a new table. Geoch. Cosmoch. Acta, 28:1273-1285.

TAYLOR, Jr., H.P. - 1980 - The effects of assimilation of country rocks by magmas on $18 \mathrm{O} /{ }^{16} \mathrm{O}$ and ${ }^{87} \mathrm{Sr} / 86 \mathrm{Sr}$ systematics in igneous rocks. Earth Planet. Sci. Lett., 47:243-254.

ULBRICH, H.H.G.J. - 1984 - A petrografia, estrutura e o quimismo de nefelina sienitos do Maciço Alcalino de Poços de Caldas, MG-SP. São Paulo. (Tese de Livre-Docência, IG-USP). $700 \mathrm{p}$.

VLACH, S.R.F. - 1985 - Geologia, petrografia e geocronologia das regióes meridional e oriental do Complexo de Morungaba, SP. São Paulo. (Dissertacão de Mestrado, IG-USP). 253 p.

VLACH, S.R.F. \& KAWASHITA, K. - 1984 - Isócronas Rb/Sr da Su fte Intrusiva de Morungaba, SP. In: CONGR. BRAS. GEOL. 33, Rio de janeiro, 1984. Resumos... Rio de Janeiro, SBG, p. 158-159.

VLACH, S.R.F. \& ULBRICH, H.H.G.J. - em prep. - Geologia e petrografia do Complexo de Morungaba, SP: partes meridional e oriental.

WHITE, A.J.R. \& CHAPPELL, B.W. - 1977 - Ultrametamorphism and granitoid genesis. Tectonophysics, 43:7-22.

WHITE, A.J.R. \& CHAPPELL, B.W. - 1983 - Granitoid types and their distribution in the Lachland Folded Belt, Southeast Australia. Geol. Soc. Amer. Spec. Pap., Memoir 159, p. 21-34.

WILLIAMSON, J.H. - 1968 - Least-squares fitting of a straightline. Canad. J. Phys., 46:1845-1847.

WYLLIE, P.J. - 1984 - Sources of granitoid magmas at convergent plate boundaries. Phys. Earth Planet. Int., 35:12-18.

ZWART, H.J. - 1967 - The duality of orogenic belts. Geol. Mijnbown, 46:283-304.

MANUSCRITO

Recebido em 17 de fevereiro de 1986 Revisão aceita em 24 de março de 1986 